\title{
Modeling of Asphaltene Precipitation from Crude Oil with the Cubic Plus Association Equation of State
}

\author{
Arya, Alay; Liang, Xiaodong; von Solms, Nicolas; Kontogeorgis, Georgios
}

Published in:

Energy and Fuels

Link to article, DOI:

10.1021/acs.energyfuels.6b02767

Publication date:

2017

Document Version

Peer reviewed version

Link back to DTU Orbit

Citation (APA):

Arya, A., Liang, X., von Solms, N., \& Kontogeorgis, G. (2017). Modeling of Asphaltene Precipitation from Crude Oil with the Cubic Plus Association Equation of State. Energy and Fuels, 31(2), 2063-2075.

https://doi.org/10.1021/acs.energyfuels.6b02767

\section{General rights}

Copyright and moral rights for the publications made accessible in the public portal are retained by the authors and/or other copyright owners and it is a condition of accessing publications that users recognise and abide by the legal requirements associated with these rights.

- Users may download and print one copy of any publication from the public portal for the purpose of private study or research.

- You may not further distribute the material or use it for any profit-making activity or commercial gain

- You may freely distribute the URL identifying the publication in the public portal 


\title{
Modeling of Asphaltene Precipitation from Crude Oil with the Cubic Plus Association Equation of State
}

\author{
Alay Arya, Xiaodong Liang, Nicolas von Solms, Georgios M. Kontogeorgis* \\ Center for Energy Resources Engineering (CERE), Department of Chemical and Biochemical \\ Engineering, Technical University of Denmark, DK-2800 Kgs. Lyngby, Denmark
}

*To whom correspondence should be addressed. Tel: 45-45252859. Fax: 45-45882258. Email: gk@kt.dtu.dk.

In this study, different modeling approaches using the Cubic Plus Association (CPA) equation of state (EoS) are developed to calculate the asphaltene precipitation onset condition and asphaltene yield from degassed crude oil during the addition of $n$-paraffin. A single model parameter is fitted to calculate the asphaltene onset condition during the addition of different $n$ paraffin precipitants ( $n$-pentane to $n$-hexadecane). Three parameters per precipitant are fitted to calculate the asphaltene yield during the addition of the precipitant. The results obtained from the model are compared with the experimental data for eight different crude oils. Results were also obtained for seven crudes using the Perturbed Chain Statistical Association Fluid Theory (PC-SAFT) EoS based approach described in the literature. The CPA EoS based approaches treat the asphaltene fraction as an associating component whereas the PC-SAFT EoS based approach does not. A comparison between the approaches shows that the CPA EoS based approaches, developed in this work, give more reliable results. The predictions from the PC-SAFT EoS based approach result in behavior that is unphysical: the mole fraction of $n$ paraffin (at the precipitation onset) and the asphaltene yield do not decrease with the carbon number of $n$-paraffin. Furthermore, it is shown that the approach, developed in this work, can predict the onset conditions of asphaltene precipitation resulting from a blend of two or more crudes.

\section{Introduction}

A crude oil at room temperature can be divided into maltene (deasphalted fraction) and asphaltene fractions. The maltene fraction can be further divided into saturates, aromatics and resins fractions. The SARA (saturates, aromatics, resins, asphaltenes) analysis is used to measure the amount (on weight basis) of these four solubility fractions. All of these fractions are polydisperse in the oil and contain a large number of components. Asphaltenes are defined as the heaviest fraction of the oil, which is not soluble in $n$-pentane/n-heptane but soluble in aromatic solvents such as toluene [1-3]. Resins are the fraction of the oil, which is soluble in $n$ pentane/ $n$-heptane, toluene and benzene but insoluble in ethyl acetate at room temperature $[2,4]$. It is believed that resins are cross-associating (form hydrogen bonds) with asphaltenes to 
keep asphaltenes soluble in the oil [5]. The asphaltene fraction may precipitate out of the crude oil during the addition of a paraffinic component. As the carbon number of $n$-paraffin increases, the solubility of the asphaltene fraction increases and the amount of precipitated asphaltenes decreases. For the higher carbon number $(>11) n$-paraffins, the amount of precipitated asphaltenes remains almost constant [5]. The asphaltenes containing crude is generally blended with one or more crudes to maintain the properties of feedstock (blended crude) to the refinery. In certain cases, the blending of incompatible crudes results in the asphaltene precipitation. The asphaltene precipitation can result in fouling and coking of preheat trains, heat exchangers and pipestill furnace tubes in the refinery [6]. Therefore, it is important to understand the asphaltene precipitation in order to avoid complications during the processing of crude oil.

There are several studies on the modeling of the asphaltene precipitation from the crude oil. Some of them consider the asphaltene fraction as polydisperse while others consider it as monodisperse. These studies can also be classified according to whether the asphaltene fraction is treated as a non-associating or an associating molecule. When the asphaltene molecule is considered not to associate with other asphaltene molecules, it is assumed that the asphaltene component already exists in a pre-aggregated form and only van der Waals forces are included in the asphaltene precipitation model. On the other hand, when the asphaltene molecule is allowed to associate with other asphaltene molecules, it is assumed that the asphaltene molecule exists as a monomer. In this case, the association between asphaltene molecules is an important criteria for precipitation, along with the van der Waals forces. This association is a way to account for strong polar forces such as hydrogen bonding. The framework of both PC-SAFT and CPA EoS allows the modelling of both van der Waals and association forces. However, we point out that the association term is not considered in this work for the PC-SAFT based model, where we follow the approach used previously in the literature [7].

\section{Asphaltene as a Non-associating and Pre-aggregated Component}

The asphaltene precipitation from the crude oil has been modeled by several researchers. Hirschberg et al [2] used the Flory-Huggins theory in order to study the effect of miscible gas flooding on the asphaltene precipitation. They used the Soave-Redlich-Kwong (SRK) EoS for vapor-liquid equilibrium considering no asphaltene precipitation. They then used the FloryHuggins model to calculate the asphaltene precipitation from the liquid phase, calculated from the SRK EoS. The asphaltene fraction was considered as a monodisperse component. Alboudwarej et al [8] used the regular Flory-Huggins model dividing the asphaltene fraction into multiple components of different molar mass, volume and solubility parameters. They assumed that the precipitated phase is ideal and consists of only the asphaltene components. 
Akbarzadeh et al [9] used the same approach developed by Alboudwarej et al [8] and showed the temperature and pressure effect on the model predictions. They used a temperature dependent gamma distribution function to describe the temperature dependent molar mass distribution of the asphaltene fraction. Pazuki and Nikookar [10] modified the Flory-Huggins model and compared the asphaltene precipitation results with the original Flory-Huggins model and experimental data. They concluded that the modified model is better than the original one. Wiehe et al [6] developed the oil compatibility model in order to check whether the blending of two or more crudes is compatible with respect to the asphaltene precipitation. Wiehe et al [11] compared the oil compatibility model with the regular Flory-Huggins theory based model from Yarranton and co-workers $[8,9]$. They concluded that both models can calculate the asphaltene onset condition as well as the maximum in volume of $n$-paraffin, as a function of the carbon number of $n$-paraffins at the onset of asphaltene precipitation. They also mentioned that the basic assumption of the oil compatibility model, that the solubility parameter of mixture at the onset is constant, contradicts the physical behavior. Tharanivasan et al [12] used the regular Flory-Huggins theory based model, developed by Yarranton and co-workers [8, 9], to calculate the asphaltene yield (ratio of mass of precipitated asphaltenes to mass of oil before addition of precipitant) as well as the onset condition of the blend of different crudes. They considered the asphaltene fraction as polydisperse components. Sabbagh et al [13] used the Peng-Robinson (PR) EoS. They divided the asphaltene fraction into multiple components of different molar masses based on the gamma distribution function. The precipitated phase was assumed to contain only the asphaltene components. They concluded that the PR model is not a universal predictor and not better than the previously developed regular solution model. Panuganti et al [14] and Tavakkoli et al [7] used a model, based on the PC-SAFT EoS, considering the asphaltene fraction as polydisperse components. They studied both light and heavy crudes. They used interaction parameters for the asphaltene-n-paraffin binary pairs in order to correlate both the onset conditions and asphaltene yield from the light crude. They kept the binary interaction parameters for asphaltene- $n$-paraffins binary pairs to a zero value in order to predict the asphaltene yield from the heavy crude, however, they used non-zero values for the binary interaction parameter of the asphaltene-saturates binary pair in order to correlate the onset conditions. Their model predictions contradict the general experimental observation $[2,15,4]$, where the amount of precipitated asphaltenes decreases or remains constant with the carbon number of $n$-paraffin precipitant. This contradiction is discussed in detail in the "Results and Discussion" section of this work.

\section{Asphaltene as an Associating and Monomeric Component}

Wu et al $[16,17]$ used the SAFT EoS in the framework of McMillan-Mayer theory. In their model, asphaltenes and resins are considered as monodisperse pure pseudo-components and the interactions between them are screened through the continuous medium of solution containing 
other components. They applied their model to calculate the asphaltene yield from the crude oil and the onset conditions from the reservoir oil. However, they did not study the onset conditions for the crudes during the addition of $n$-paraffin. Buenrostro-Gonzalez et al [15] modified the modeling approach of Wu et al $[16,17]$ by using the SAFT-VR instead of the SAFT EoS. They applied their model to calculate both the onset conditions and asphaltene yields from the crude. However, they could not match both types of experimental data with the single set of parameters. Li and Firoozabadi [18] developed a modeling approach based on the CPA EoS considering the asphaltene fraction as a monodisperse component. They studied the asphaltene precipitation from the heavy oil. They did not study their modeling approach with respect to the asphaltene onset condition from the crude oil.

To our knowledge, nobody has so far studied the CPA equation of state for the asphaltene precipitation from the crude considering the asphaltene fraction as polydisperse. There is also no study on the blending of crudes with the CPA and PC-SAFT equations of state. In this study, different CPA approaches are developed to study the asphaltene yield and onset conditions. The PC-SAFT approach is referred from Tavakkoli et al [7]. Both CPA and PC-SAFT approaches are studied and compared with the experimental data. A total of eight crudes are studied. Crude- 1 is studied with respect to both the asphaltene yield and onset conditions considering the asphaltene fraction as a polydisperse fraction. Crude- 2 to 4 are studied with respect to asphaltene yield considering the asphaltene fraction as a polydisperse fraction, while Crude- 5 to 8 are studied with respect to onset conditions considering the asphaltene fraction as a monodisperse fraction. The brief introduction about the CPA EoS is given here in order to familiarize the reader about model parameters. The reader can refer to the supplementary information for more details on the PC-SAFT EoS.

\section{CPA EOS}

The CPA EoS, proposed by Kontogeorgis et al [19], can be expressed for mixtures in terms of pressure $P$, as shown in equation (1). Please consult the "List of Symbol" and "Greek Letters" sections for the meaning of each symbols used in the following equations.

$$
\begin{aligned}
& P=\frac{R T}{V_{m}-b}-\frac{a(T)}{V_{m}\left(V_{m}+b\right)}-\frac{1}{2} \frac{R T}{V_{m}}\left(1+\rho \frac{\partial \ln g}{\partial \rho}\right) \sum_{i} x_{i} \sum_{A_{i}}\left(1-X_{A_{i}}\right) \\
& a(T)=\sum_{i} \sum_{j} x_{i} x_{j} a_{i j}(T) \\
& a_{i j}(T)=\sqrt{a_{i}(T) a_{j}(T)}\left(1-k_{i j}\right)
\end{aligned}
$$


When the CPA EoS is used for mixtures, the conventional mixing rules are employed in the physical term (SRK) for the energy and co-volume parameters. The geometric mean rule is used for the energy parameter $a_{i j}(T)$. The interaction parameter $k_{i j}$ is the only binary adjustable parameter of CPA in the applications for self-associating mixtures, e.g. glycol with n-alkanes.

The energy parameter of the EoS is given by a Soave-type temperature dependency, while $b$ is temperature independent:

$$
a_{i}(T)=a_{0, i}\left[1+c_{1, i}\left(1-\sqrt{\frac{T}{T_{c, i}}}\right)\right]^{2}
$$

where $T_{c, i}$ is the critical temperature of the $i^{\text {th }}$ component.

The key element of the association term is $X_{A_{i}}$, which represents the mole fraction of site-A in molecule of component $i$ not bonded to other sites, while $x_{i}$ is the mole fraction of component $i$. $\mathrm{X}_{\mathrm{A}_{\mathrm{i}}}$ is related to the association strength $\Delta^{\mathrm{A}_{\mathrm{i}} \mathrm{B}_{\mathrm{j}}}$ between two sites belonging to two different molecules, e.g. site A on molecule $i$ and site B on molecule $j$, determined from:

$$
X_{A_{i}}=\frac{1}{1+\rho \sum_{j} x_{j} \sum_{B_{j}} X_{B_{j}} \Delta^{A_{i} B_{j}}}
$$

where the association strength $\Delta^{\mathrm{A}_{\mathrm{i}} \mathrm{B}_{\mathrm{j}}}$ in CPA is expressed as:

$$
\Delta^{A_{i} B_{j}}=g(\rho)\left[\exp \left(\frac{\varepsilon^{A_{i} B_{j}}}{R T}\right)-1\right] b_{i j} \beta^{A_{i} B_{j}}
$$

where:

$$
b_{i j}=\frac{b_{i}+b_{j}}{2}
$$

with the radial distribution function:

$$
g(\rho)=\frac{1}{1-1.9 n}, n=\frac{1}{4} b \rho
$$

In the expression for the association strength $\Delta^{A_{i} B_{j}}$, the parameters $\varepsilon^{A_{i} B_{j}}$ and $\beta^{A_{i} B_{j}}$ are called the association energy and the association volume, respectively. These two parameters are used only for associating components, and along with the three additional parameters of the SRK term $\left(a_{0}, b, c_{1}\right)$, they are the five pure-compound parameters of the model. They are obtained by fitting vapor pressure and liquid density data. For inert components such as hydrocarbons, only the three parameters of the SRK term are required, which can either be obtained from vapor pressures and liquid densities or be calculated in the conventional manner (from critical data, acentric factor).

Following are the combining rules (CR), which are required for cross-associating systems. CR-1 and Elliott CR are generally used. Modified CR-1 and Customized CR-1 are used for solvating systems only. 
(i) CR-1:

$$
\varepsilon^{A_{i} B_{j}}=\frac{\varepsilon^{A_{i} B_{i}}+\varepsilon^{A_{j} B_{j}}}{2}, \quad \beta^{A_{i} B_{j}}=\sqrt{\beta^{A_{i} B_{i}} \beta^{A_{j} B_{j}}}
$$

(ii) Elliott CR:

$$
\Delta^{A_{i} B_{j}}=\sqrt{\Delta^{A_{i} B_{i}} \Delta^{A_{j} B_{j}}}
$$

(iii) Modified CR-1:

Cross association volume $\beta^{A_{i} B_{j}}$ is fitted to experimental data and CR-1 rule is used for cross association energy $\varepsilon^{\mathrm{A}_{\mathrm{i}} \mathrm{B}_{\mathrm{j}}}$.

(iv) Customized CR-1:

Cross association volume $\beta^{A_{i} B_{j}}$ and cross association energy $\varepsilon^{A_{i} B_{j}}$ are fitted to experimental data.

\section{Modeling Approaches}

\section{Approach-1}

Approach-1 is based on the CPA EoS and is the same approach as was proposed by Arya et al [20-22]. As shown in Table 1, the modeling approach-1 has a single component for the maltene fraction and six components for the asphaltene fraction. The asphaltene components are considered self-associating with two positive and two negative sites on each asphaltene molecules. The maltene component's molecule has one association site and can crossassociate with both positive and negative sites of the asphaltene components. The maltene component is not self-associating. The critical temperature and pressure $\left(T_{c}, P_{c}\right)$ and acentric factor $(\omega)$ of maltene component are calculated from the Kesler-Lee correlations [23] based on the information of normal boiling point, molecular weight (MW) and specific gravity (SG). The MW and SG of maltene component are calculated from the experimental information of MW and SG of the crude and asphaltenes MW (750 Da) and SG (1.2 g/cc). The normal boiling point is calculated from the Pedersen correlation [24]. The critical temperature and pressure $\left(T_{c}, P_{c}\right)$, acentric factor $(\omega)$ and self-association volume are constant for all six asphaltene components and are referred from Arya et al [20-22]. The self-association energies of asphaltene components (Asp-4 to Asp6) are also kept constant to reduce the number of model parameters. In addition the self-association energies of asphaltene components (Asp1 to Asp3) are 
assumed to be same. The cross-association volume between the asphaltenes and maltene is also fixed to the value of 0.05 .

Mitchell and Speight [4] mentioned that the asphaltene yield decreases with the carbon number of $n$-paraffin. However, approach-1 cannot predict this physical behavior and precipitate all asphaltene components (Asp1 to 6) irrespective of the carbon number of $n$ paraffin. To overcome this issue, one more model parameter is incorporated, which is the crossassociation energy between the $n$-paraffin and asphaltene components (except Asp6). It means that Asp1 to Asp5 have the same cross-association energy with a given $n$-paraffin. By doing this, the solubility of Asp1 in $n$-paraffin is higher than those of other asphaltene components (Asp2 to Asp5) in $n$-paraffin since the self-association energy of Asp1 is lower than those of other asphaltene components. If the cross-association energy for a given $n$-paraffin increases, the solubility of all asphaltene components (with fixed self-association energies) in a given $n$ paraffin increases. Therefore, we can assign the higher value of the cross-association energy for $n$-paraffin precipitant as the carbon number increases and can correlate the asphaltene yield data. Li and Firoozabadi [18] also studied the CPA EoS for the calculations of asphaltene yield from the crude and they suggested that the cross-association energy between $(A+R)$ and asphaltenes is different for different $n$-paraffins. They have not considered any crossassociation between $n$-paraffin and asphaltenes. However, in our approach, the crossassociation energy between aromatics+resins $(A+R) /$ maltene and asphaltenes is the same for different $n$-paraffins and the cross-association energy between $n$-paraffin and asphaltenes is different for different $n$-paraffins. Speight [25] mentioned that the asphaltene yield is almost constant for $n$-paraffin of higher carbon number (around $>11$ ). Therefore, Asp6 component is treated as an $n$-paraffin undissolved asphaltene fraction and does not cross-associate with the $n$-paraffin precipitant. Thus, approach-1 needs two additional model parameters (the crossassociation energy between the precipitant and asphaltene components and amount of Asp6). It should be noted that the binary interaction parameter $\left(k_{i j}\right)$ between the $n$-paraffin and asphaltenes pair could also be used instead of the cross-association energy between them. However, it needs some modification of the modeling approach and is not shown in this work. In addition, one could also fix the amount of Asp6 for all crudes, for example $30 \%$ of asphaltenes amount from SARA analysis, which would result in minor deviations from the experimental data. Table 2 shows that there are total three model adjustable parameters (MAP1, MAP2, and MAP3). The model parameter MAP3 is different for different $n$-paraffins. 
Table 1

Approach-1: Crude oil characterization and components parameters.

\begin{tabular}{|c|c|c|c|c|c|c|c|c|}
\hline \multirow[t]{2}{*}{ Comp } & Amount & MW & $T_{c}$ & $P_{c}$ & $\omega$ & $\begin{array}{c}\text { Self- } \\
\text { association } \\
\text { energy } \\
\left(\varepsilon^{A A} / R\right)\end{array}$ & $\begin{array}{c}\text { Self- } \\
\text { association } \\
\text { volume } \\
\left(\beta^{A A}\right)\end{array}$ & $\begin{array}{l}\text { No. Of } \\
\text { Sites }\end{array}$ \\
\hline & wt $\%$ & $\mathrm{~g} / \mathrm{mol}$ & $\mathrm{K}$ & bar & - & $(\mathrm{K})$ & - & - \\
\hline Maltene & $\mathrm{X}^{\mathrm{a}}$ & Calc $^{d}$ & Calc $^{d}$ & Calc $^{d}$ & Calc $^{d}$ & 0 & 0 & $1^{f}$ \\
\hline Asp1 & $\mathrm{Y}^{\mathrm{b}}$ & 750 & 1040.1 & 15.44 & 1.535 & MAP1e & 0.05 & $2+, 2-$ \\
\hline Asp2 & $Y^{b}$ & 750 & 1040.1 & 15.44 & 1.535 & MAP1e & 0.05 & $2+, 2-$ \\
\hline Asp3 & $Y^{b}$ & 750 & 1040.1 & 15.44 & 1.535 & MAP1e & 0.05 & $2+, 2-$ \\
\hline Asp4 & $\mathrm{Y}^{\mathrm{b}}$ & 750 & 1040.1 & 15.44 & 1.535 & 6500 & 0.05 & $2+, 2-$ \\
\hline Asp5 & $\mathrm{Y}^{\mathrm{b}}$ & 750 & 1040.1 & 15.44 & 1.535 & 6600 & 0.05 & $2+, 2-$ \\
\hline Asp6 & $\mathrm{Z}^{\mathrm{c}}(\mathrm{MAP})^{\mathrm{e}}$ & 750 & 1040.1 & 15.44 & 1.535 & 7000 & 0.05 & $2+, 2-$ \\
\hline \multicolumn{9}{|c|}{ a $\mathrm{X}$ is the sum of wt $\%$ of saturates, aromatics and resins from SARA analysis. } \\
\hline \multicolumn{9}{|c|}{ b $\mathrm{Y}=($ Asp wt\% from $S A R A-\mathrm{Z}) / 5$} \\
\hline \multicolumn{9}{|c|}{${ }^{\mathrm{c}} \mathrm{Z}$ is the amount of asphaltene sub-fraction (Asp6), which is not dissolved in $n$-paraffin. } \\
\hline \multicolumn{9}{|c|}{ d Calculated (Calc) from the Kesler-Lee correlations as mentioned in the text. } \\
\hline \multicolumn{9}{|c|}{ e Model Adjustable Parameter (MAP) determined from the experimental data. } \\
\hline Maltene & cule has c & $\because$ & & 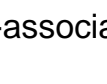 & . & ive & & \\
\hline
\end{tabular}

Table 2

Approach-1: Self-association and Cross-association energy parameter in Kelvin. ${ }^{\mathrm{b}}$

\begin{tabular}{|c|c|c|c|c|c|c|c|c|}
\hline & Asp1 & Asp2 & Asp3 & Asp4 & Asp5 & Asp6 & Maltene & $n$-paraffin \\
\hline Asp1 & MAP1 $^{a}$ & Elliott & Elliott & Elliott & Elliott & Elliott & MAP2 a & MAP3 $^{a}$ \\
\hline Asp2 & Elliott & MAP1 ${ }^{a}$ & Elliott & Elliott & Elliott & Elliott & MAP2 a & MAP3 a \\
\hline Asp3 & Elliott & Elliott & MAP1 ${ }^{a}$ & Elliott & Elliott & Elliott & MAP2 a & MAP3 a \\
\hline Asp4 & Elliott & Elliott & Elliott & 6500 & Elliott & Elliott & MAP2 a & MAP3 a \\
\hline Asp5 & Elliott & Elliott & Elliott & Elliott & 6600 & Elliott & MAP2 a & MAP3 ${ }^{a}$ \\
\hline Asp6 & Elliott & Elliott & Elliott & Elliott & Elliott & 7000 & MAP2 a & 0 \\
\hline Maltene & MAP2 a & MAP2 ${ }^{a}$ & MAP2 a & MAP2 a & MAP2 a & MAP2 a & 0 & 0 \\
\hline$n$-paraffin & MAP3 ${ }^{a}$ & MAP3 $^{a}$ & MAP3 ${ }^{a}$ & MAP3 a & MAP3 a & 0 & 0 & 0 \\
\hline
\end{tabular}

a Model Adjustable Parameters (MAP1, MAP2 and MAP3) determined from the experimental data of asphaltene yield and onset conditions.

${ }^{b}$ Cross-association volume is 0.05 for all pairs where Elliott combining rule is not used.

\section{Approach-2}

Approach-2 is based on the CPA EoS and similar to approach-1, except for a few differences, and is shown in Table 3. In approach-2, the maltene fraction is divided into saturates and $(A+R)$ components. The critical temperature and pressure $\left(T_{c}, P_{c}\right)$, acentric factor $(\omega)$ and $\mathrm{MW}$ are fixed for all components and are taken from Li and Firoozabadi [18]. For asphaltenes MW, the value of $750 \mathrm{Da}$ is used in this study, whereas Li and Firoozabadi [18] used the value of $1800 \mathrm{Da}$. Sabbagh et al [13] showed the relationship between MW and critical temperature and pressure $\left(T_{c}, P_{c}\right)$ and acentric factor $(\omega)$, which were then used by Li and Firoozabadi [18]. There are two 
reasons for the development of approach-2 over approach-1. The first reason is to show that the maltene fraction can further be divided into two components (and possibly more) and model can still be fitted to the experimental data. The second reason is to use the different set of component parameters, derived based on the information of experimental MW from the vapor pressure osmometry technique, for the heavy oil from the literature. Table 4 shows that there are total three model adjustable parameters (MAP1, MAP2, and MAP3). The model parameter MAP3 is different for different $n$-paraffins.

Table 3

Approach-2: Crude oil characterization and components parameters.

\begin{tabular}{|c|c|c|c|c|c|c|c|c|}
\hline Comp & Amount & MW & $T_{c}$ & $P_{c}$ & $\omega$ & $\begin{array}{c}\text { Self- } \\
\text { association } \\
\text { energy } \\
\left(\varepsilon^{A A} / R\right)\end{array}$ & $\begin{array}{l}\text { Self-association } \\
\text { volume }\left(\beta^{A A}\right)\end{array}$ & $\begin{array}{c}\text { No. Of } \\
\text { Sites }\end{array}$ \\
\hline Saturates & $\mathrm{X} 1^{\mathrm{a}}$ & 460 & 930 & 13.4 & 09 & 0 & 0 & 0 \\
\hline$A+R$ & $X 2^{b}$ & 660 & 1074 & 10.85 & 1.5 & 0 & 0.05 & $1^{f}$ \\
\hline Asp1 & $Y^{c}$ & 750 & 1474 & 7.07 & 2 & MAP1e & 0.05 & $2+, 2-$ \\
\hline Asp2 & $Y^{c}$ & 750 & 1474 & 7.07 & 2 & MAP1e & 0.05 & $2+, 2-$ \\
\hline Asp3 & $Y^{c}$ & 750 & 1474 & 7.07 & 2 & MAP1e & 0.05 & $2+, 2-$ \\
\hline Asp4 & $\mathrm{Y}^{\mathrm{c}}$ & 750 & 1474 & 7.07 & 2 & 6500 & 0.05 & $2+, 2-$ \\
\hline Asp5 & $\mathrm{Y}^{\mathrm{c}}$ & 750 & 1474 & 7.07 & 2 & 6600 & 0.05 & $2+, 2-$ \\
\hline Asp6 & $Z^{\mathrm{d}}(\mathrm{MAP})^{\mathrm{e}}$ & 750 & 1474 & 7.07 & 2 & 7000 & 0.05 & $2+, 2-$ \\
\hline \multicolumn{9}{|c|}{ a $\mathrm{X} 1$ is the $w t \%$ of saturates from SARA analysis. } \\
\hline \multicolumn{9}{|c|}{${ }^{b} \mathrm{X} 2$ is the sum of wt\% of aromatics and resins from SARA analysis. } \\
\hline \multicolumn{9}{|c|}{${ }^{\mathrm{c}} \mathrm{Y}=($ Asp $w t \%$ from $S A R A-\mathrm{Z}) / 5$. } \\
\hline \multicolumn{9}{|c|}{$\mathrm{d} \mathrm{Z}$ is the amount of asphaltene sub-fraction (Asp6), which is not dissolved in $n$-paraffin. } \\
\hline \multicolumn{9}{|c|}{ e Model Adjustable Parameter (MAP1) determined from the experimental data. } \\
\hline \multicolumn{9}{|c|}{$\begin{array}{l}f(A+R) \text { molecule has one site, which can cross-associate with both positive and negative sites of asphaltene } \\
\text { molecule. }\end{array}$} \\
\hline
\end{tabular}

Table 4

Approach-2: Self-association and Cross-association energy parameters in Kelvin. ${ }^{b}$

\begin{tabular}{|c|c|c|c|c|c|c|c|c|c|}
\hline & Asp1 & Asp2 & Asp3 & Asp4 & Asp5 & Asp6 & saturates & $A+R$ & $n$-paraffin \\
\hline Asp1 & MAP1 ${ }^{a}$ & Elliott & Elliott & Elliott & Elliott & Elliott & 0 & MAP2 a & MAP3 $^{a}$ \\
\hline Asp2 & Elliott & MAP1 ${ }^{a}$ & Elliott & Elliott & Elliott & Elliott & 0 & MAP2 a & MAP3 a \\
\hline Asp3 & Elliott & Elliott & MAP1 $^{a}$ & Elliott & Elliott & Elliott & 0 & MAP2 a & MAP3 a \\
\hline Asp4 & Elliott & Elliott & Elliott & 6500 & Elliott & Elliott & 0 & MAP2 a & MAP3 ${ }^{a}$ \\
\hline Asp5 & Elliott & Elliott & Elliott & Elliott & 6600 & Elliott & 0 & MAP2 a & MAP3 a \\
\hline Asp6 & Elliott & Elliott & Elliott & Elliott & Elliott & 7000 & 0 & MAP2 ${ }^{a}$ & 0 \\
\hline saturates & 0 & 0 & 0 & 0 & 0 & 0 & 0 & 0 & 0 \\
\hline$A+R$ & MAP2 a & MAP2 a & MAP2 a & MAP2 a & MAP2 a & MAP2 a & 0 & 0 & 0 \\
\hline$n$-paraffin & MAP3 ${ }^{a}$ & MAP3 & MAP3 $^{a}$ & MAP3 ${ }^{a}$ & MAP3 ${ }^{a}$ & 0 & 0 & 0 & 0 \\
\hline
\end{tabular}

a Model Adjustable Parameters (MAP1, MAP2 and MAP3) determined from the experimental data of asphaltene yield and onset conditions.

${ }^{b}$ Cross-association volume is 0.05 for all pairs where Elliott combining rule is not used. 


\section{Approach-3}

If we are only interested in calculating the precipitation onset condition, we can reduce the number of components and therefore the number of model adjustable parameters. Approach3 is based on the CPA EoS and is similar to approach-2. Approach-3 has only one asphaltene component as shown in Table 5 . There is no cross-association between the precipitant and asphaltene component but the cross-association between (A+R) and asphaltene components is present. Moreover, the self-association energy of asphaltene is fixed to $3000 \mathrm{~K}$ (instead of $7000 \mathrm{~K}$ ) to show that the relative balance between the asphaltene and solvent is important rather than the absolute values of asphaltene self-association energy and cross-association energy of solvent. In other words, there can be multiple pairs of values of the asphaltene selfassociation energy and cross-association energy (between $(A+R)$ and asphaltene components), which can correlate the experimental data. The experimental values of MW are used, if they are available, without changing the critical temperature and pressure $\left(T_{c}, P_{c}\right)$, acentric factor $(\omega)$ for saturates and $(A+R)$ components. Table 6 shows that there is only one model adjustable parameter (MAP1).

\section{Table 5}

Approach-3: Crude oil characterization and components parameters.

\begin{tabular}{|c|c|c|c|c|c|c|c|c|}
\hline Comp & Amount & MW & $T_{c}$ & $P_{c}$ & $\omega$ & $\begin{array}{c}\text { Self- } \\
\text { association } \\
\text { energy }\left(\varepsilon^{A A} / R\right)\end{array}$ & $\begin{array}{l}\text { Self-association } \\
\text { volume }\left(\beta^{A A}\right)\end{array}$ & $\begin{array}{l}\text { No. Of } \\
\text { Sites }\end{array}$ \\
\hline & wt $\%$ & $\mathrm{~g} / \mathrm{mol}$ & $\mathrm{K}$ & bar & - & $(\mathrm{K})$ & - & - \\
\hline Saturates & $\mathrm{X} 1^{\mathrm{a}}$ & 460 & 930 & 13.4 & 0.9 & 0 & 0 & 0 \\
\hline$A+R$ & $\mathrm{X} 2^{\mathrm{b}}$ & 660 & 1074 & 10.85 & 1.5 & 0 & 0.05 & $1^{d}$ \\
\hline Asp & $\mathrm{X} 3^{\mathrm{c}}$ & 750 & 1474 & 7.07 & 2 & 3000 & 0.05 & $2+, 2-$ \\
\hline
\end{tabular}

a $\mathrm{X} 1$ is the wt\% of saturates from SARA analysis.

${ }^{b} \mathrm{X} 2$ is the sum of $w t \%$ of aromatics and resins from SARA analysis.

${ }^{c} \mathrm{X} 3$ is the wt\% of asphaltene from SARA analysis.

d $(A+R)$ molecule has one site, which can cross-associate with both positive and negative sites of asphaltene molecule.

Table 6

Approach-3: Self-association and Cross-association energy parameters in Kelvin. ${ }^{b}$

\begin{tabular}{ccccc}
\hline & Asp & saturates & A+R & $n$-paraffin \\
\hline Asp & 3000 & 0 & MAP1 ${ }^{\text {a }}$ & 0 \\
saturates & 0 & 0 & 0 & 0 \\
A+R & MAP1 a & 0 & 0 & 0 \\
$n$-paraffin & 0 & 0 & 0 & 0 \\
\hline
\end{tabular}

a Model Adjustable Parameter (MAP1) determined from the experimental data of asphaltene onset condition.

b Cross-association volume is 0.05 for all pairs. 


\section{Approach-4}

Approach-4 is based on the PC-SAFT EoS and no association term is used since there is no associating component. Approach-4 is the same approach as was developed by Tavakkoli et al [7]. In approach-4, the crude is divided into saturates, $A+R$ and multiple components of the asphaltene fraction. The number of asphaltene components depends upon the experimental data of different $n$-paraffins undissolved asphaltene amounts. For example, if the experimental data of $n C 5, n C 7$ and $n C 10$ undissolved asphaltene amounts are available, three asphaltene components ( $n C 5$ insoluble but $n C 7$ soluble asphaltene fraction, $n C 7$ insoluble but $n C 10$ soluble asphaltene fraction and $n C 10$ insoluble asphaltene fraction) are used. The PC-SAFT parameters of saturates components are calculated from the MW correlations developed from the homologous series of $n$-paraffin. The standard $n$-paraffin PC-SAFT parameters from Gross and Sadowski [26] are used for this approach. The PC-SAFT parameters of the (A+R) and asphaltene components are also calculated from the $\mathrm{MW}$ and aromaticity $(\gamma)$ correlations developed from the polynuclear aromatic components by Gonzalez et al [27]. The zero value of aromaticity $(\gamma)$ corresponds to benzene derivatives and value of unity corresponds to polynuclear aromatics. Both correlations are mentioned in Table 7 . The aromaticity value of $(A+R)$ is tuned to match density of the crude. The aromaticity $(\gamma)$ values of all asphaltene components are assumed to be the same considering they have the same physical nature. The single value of aromaticity $(\gamma)$ and respective value of MW of all asphaltene components are tuned to match the precipitation data. In addition, binary interaction parameters $\left(k_{i j} \mathrm{~s}\right)$ are also used to match the precipitation data. Tavakkoli et al [7] also tuned the segment diameter $\sigma$ of asphaltenes to find a good match with the experimental data. However, the segment diameter $\sigma$ is not used as an adjustable parameter in approach-4 in order to reduce the number of fitting parameters. When we are only interested in onset conditions, one asphaltene component, like approach-3, is used for approach-4 rather than dividing it into multiple components. Also, when the experimental MW of aromatics and resins fractions are available, $(A+R)$ component can be divided into aromatics and resins components with the same value of aromaticity $(\gamma)$.

\section{Table 7}

Approach-4: Empirical correlations for the estimation of the PC-SAFT parameters for saturates and mixture of Polynuclear Aromatics (PNA) and benzene derivative components from Panuganti et al [14].

\begin{tabular}{ll}
\hline Correlation for Saturates & $(\gamma)$ PNA correlation $+(1-\gamma)$ benzene derivatives correlation \\
\hline$m=0.0257 \times M W+0.8444$ & $m=(1-\gamma)[0.0223 \times M W+0.751]+\gamma[0.0101 \times M W+1.7296]$ \\
$\sigma(\AA)=4.047-\frac{4.8013 \times \ln (M W)}{M W}$ & $\sigma(\AA)=(1-\gamma)\left[4.1377-\frac{38.1483}{M W}\right]+\gamma\left[4.6169-\frac{93.98}{M W}\right]$ \\
$\ln (\epsilon / k)$ in $K=5.5769-\frac{9.523}{M W}$ & $(\epsilon / k)$ in $K=(1-\gamma)[0.00436 \times M W+283.93]+\gamma\left[508-\frac{234100}{(M W)^{1.5}}\right]$ \\
\hline
\end{tabular}




\section{Results and Discussion}

In this work, a total of eight different crudes are studied. The composition and properties of the crudes are mentioned in Table 8. Crudes-1, 2 and 8 are light crudes whereas Crudes- 3 to 7 are relatively heavy crudes. The model parameters for the CPA EoS based approaches- 1 to 3 , calculated from the experimental data, and are shown in Tables 9 and 10. The model parameters and characterization of the crudes for approach-4 are shown in Tables 11 and 12. The binary interaction parameters $\left(k_{i j} \mathrm{~s}\right)$ used for approach-4 are shown in Table 13. The experimental and calculated density using approach-4, after tuning the aromaticity $(\gamma)$ of $A+R$ component, are compared in Table 14. For approaches-1 to 3, Peneloux volume corrections are used for the $n$-paraffin unless otherwise mentioned. It should be noted that no $k_{i j}$ parameter is used for approaches-1 to 3. For all the crudes (except Crude-2), one of the CPA EoS based approaches- 1 to 3 and the PC-SAFT EoS based approach- 4 are compared with experimental data. For Crude-2, only approach-1 is studied. For Crudes-1, 3, and 4, the PC-SAFT parameters and oil characterization for approach-4 are referred from Tavakkoli et al [7]. For Crudes- 5 to 8 , the PC-SAFT parameters for approach-4 are from this work. Table 15 shows the comparison of the number of model adjustable parameters between the approaches for all the crudes. Approaches- 1 and 2 are used for Crudes- 1 and 2 and Crudes- 3 and 4 respectively. One can also use either approach-1 or approach-2 for Crudes-1 to 4 but results are not presented here. Since we are only interested in onset conditions, approach-3 (instead of approaches-1 and 2) is used for Crudes- 5 to 8 . 
Table 8

Experimental data of composition, MW and density of all crudes.

\begin{tabular}{|c|c|c|c|c|c|c|c|c|c|}
\hline \multicolumn{2}{|c|}{ Crude } & 1 & 2 & 3 & 4 & 5 & 6 & 7 & 8 \\
\hline \multirow{6}{*}{ Composition } & Volatile & - & - & - & - & - & - & 12.6 & 25.7 \\
\hline & Saturates & $-a$ & 54.67 & 25 & 20.5 & 19.5 & 16.4 & 25.3 & 34.2 \\
\hline & Aromatics & $-a$ & 28.89 & 31.1 & 38 & 38.2 & 40.1 & 40.9 & 33.5 \\
\hline & Resins & $-a$ & 12.66 & 37.1 & 19.6 & 26.8 & 28.7 & 4.9 & 3.2 \\
\hline & $n C 5$ Asphaltenes & 3.9 & 3.8 & 6.8 & 21.8 & 15.5 & 14.8 & 16.3 & 3.5 \\
\hline & solids & - & - & - & 0.1 & - & - & - & - \\
\hline \multirow{6}{*}{$\begin{array}{l}\text { MW } \\
\text { (Da) }\end{array}$} & Volatile & - & - & - & - & - & - & 86 & 86 \\
\hline & Saturates & - & - & 361 & 400 & 508 & 524 & 460 & 460 \\
\hline & Aromatics & - & - & 450 & 508 & 522 & 550 & 522 & 522 \\
\hline & Resins & - & - & 1108 & 1090 & 930 & 976 & 1040 & 1040 \\
\hline & Asphaltenes & - & - & 7065 & 7662 & 2850 & 2910 & - & - \\
\hline & Crude & 221.5 & 238.1 & - & - & - & - & - & - \\
\hline \multirow{6}{*}{$\begin{array}{l}\text { Density } \\
(g / c c)\end{array}$} & Volatile & - & - & - & - & - & - & 0.657 & 0.657 \\
\hline & Saturates & - & - & 0.853 & 0.882 & 0.882 & 0.885 & 0.880 & 0.880 \\
\hline & Aromatics & - & - & 0.972 & 0.997 & 0.995 & 1.003 & 0.990 & 0.990 \\
\hline & Resins & - & - & 1.066 & 1.052 & 1.037 & 1.040 & 1.044 & 1.044 \\
\hline & $n C 5$ Asphaltenes & - & - & 1.192 & 1.193 & 1.203 & 1.203 & - & - \\
\hline & Crude & 0.873 & 0.857 & 0.982 & 1.016 & 0.991 & 0.995 & 0.924 & 0.870 \\
\hline
\end{tabular}

a Molar composition of saturates (50 mol\%), aromatics (25 mol\%) and hetero-compounds (25 mol\%) are given in reference [2]

Table 9

The model adjustable parameters for Crudes-1 to 4 for the CPA EoS based approaches-1 and 2.

\begin{tabular}{|c|c|c|c|c|c|c|c|c|c|c|c|c|}
\hline \multirow{2}{*}{ Crude } & \multicolumn{3}{|c|}{$\begin{array}{l}\text { Self-association Energy } \\
\left(\varepsilon^{A A} / R \text { in } \mathrm{K}\right)\end{array}$} & \multicolumn{8}{|c|}{ Cross-association Energy (K) } & \multirow{2}{*}{$\begin{array}{l}\text { Asp-6 } \\
\text { (wt\%) }\end{array}$} \\
\hline & Asp-1 & Asp-2 & Asp-3 & Maltene & $A+R$ & $n C 5$ & $n C 7$ & $n C 9$ & $n C 10$ & $n C 12$ & $n C 16$ & \\
\hline 1 & 6450 & 6450 & 6450 & 3670 & - & 2400 & 2970 & - & 3135 & 3135 & 3135 & 1.2 \\
\hline 2 & 6000 & 6000 & 6000 & 3480 & - & 2000 & 2610 & 2720 & - & 2920 & - & 0.5 \\
\hline 3 & 6100 & 6100 & 6100 & - & 3440 & 1950 & 2380 & - & - & - & - & 0.5 \\
\hline 4 & 6430 & 6430 & 6430 & - & 3580 & 2300 & 2550 & - & - & - & - & 2 \\
\hline
\end{tabular}


Table 10

The model adjustable parameters for Crudes- 5 to 8 for the CPA EoS based approach- 3 .

\begin{tabular}{ccccc}
\hline \multirow{2}{*}{ Crude } & $\begin{array}{c}\text { Self-association Energy } \\
(\mathrm{K})\end{array}$ & & \multicolumn{2}{c}{ Cross-association Energy (K) } \\
\cline { 2 - 2 } & Asphaltenes & & A+R & Toluene \\
\hline 5 & Default & 1810 & - \\
6 & Default & 1845 & - \\
7 & Default & 1860 & 1410 \\
8 & 2600 & & 1690 & 1260 \\
\hline
\end{tabular}

Table 11

Characterization of Crudes-1, 3 and 4 for the PC-SAFT EoS based approach-4 referred from Tavakkoli et al [7].

\begin{tabular}{|c|c|c|c|c|c|c|c|c|c|}
\hline \multirow{2}{*}{ Components } & \multicolumn{3}{|c|}{ Crude-1 } & \multicolumn{3}{|c|}{ Crude-3 } & \multicolumn{3}{|c|}{ Crude-4 } \\
\hline & MW (Da) & $\gamma$ & wt\% & MW (Da) & $\gamma$ & wt $\%$ & MW (Da) & $\gamma$ & wt $\%$ \\
\hline Saturates & 207.43 & 0 & 46.8 & 361 & 0 & 25 & 400 & 0 & 20.5 \\
\hline Aromatics & - & - & - & 450 & 0.23 & 31.1 & 508 & 0.3 & 38 \\
\hline Resins & - & - & - & 1108 & 0.23 & 37.1 & 1090 & 0.3 & 19.6 \\
\hline Aromatic+Resins & 219.44 & 0.38 & 49.3 & - & - & - & - & - & - \\
\hline $\begin{array}{c}n C 5-n C 7 \\
\text { Asphaltenes }\end{array}$ & 2900 & 0.2 & 2 & 4700 & 0.2 & 2.2 & 2500 & 0.4 & 4.3 \\
\hline $\begin{array}{l}n C 7-n C 10 \\
\text { Asphaltenes }\end{array}$ & 2950 & 0.2 & 0.4 & - & - & - & - & - & - \\
\hline $\begin{array}{c}n C 7 \\
\text { Asphaltenes }\end{array}$ & - & - & - & 5600 & 0.2 & 4.6 & 2600 & 0.4 & 17.5 \\
\hline $\begin{array}{c}n C 10 \\
\text { Asphaltenes }\end{array}$ & 4307 & 0.2 & 1.5 & - & - & - & - & - & - \\
\hline
\end{tabular}

Table 12

The parameters for Crudes- 5 to 8 for the PC-SAFT EoS based approach- 4 from this work.

\begin{tabular}{|c|c|c|c|c|c|}
\hline \multirow{2}{*}{ Crude } & \multicolumn{3}{|c|}{ MW (Da) } & \multicolumn{2}{|c|}{$\gamma$} \\
\hline & Saturates & $A+R$ & Asp & $A+R$ & Asp \\
\hline 5 & 508 & 637.3 & 2850 & 0.32 & 0.37 \\
\hline 6 & 524 & 672.4 & 2910 & 0.32 & 0.37 \\
\hline 7 & 460 & 800 & 6350 & 0.38 & 0.18 \\
\hline 8 & 460 & 800 & 5200 & 0.30 & 0.25 \\
\hline
\end{tabular}


Table 13

The binary interaction $\left(\boldsymbol{k}_{\boldsymbol{i j}}\right)$ parameters used for the PC-SAFT EoS based approach-4 for different crudes. For Crudes 1 and 4, parameters are from Tavakkoli et al [7].

\begin{tabular}{|c|c|c|c|c|c|c|c|}
\hline Crude & Component & $n C 5$ & $n C 7$ & $n C 10$ & $n C 12$ & $n C 16$ & Saturates \\
\hline \multirow{4}{*}{1} & $\begin{array}{l}\text { Aromatic+ } \\
\text { Resins }\end{array}$ & 0.007 & 0.0065 & 0.006 & 0.006 & 0.005 & 0.007 \\
\hline & $\begin{array}{c}n C 5-n C 7 \\
\text { Asphaltenes }\end{array}$ & $0.01^{a}$ & $0.007^{\mathrm{a}}$ & 0.006 & 0.005 & 0.005 & 0.003 \\
\hline & $\begin{array}{l}n C 7-n C 10 \\
\text { Asphaltenes }\end{array}$ & $0.01^{a}$ & $0.007^{a}$ & 0.006 & 0.005 & 0.005 & 0.003 \\
\hline & $\begin{array}{c}n C 10 \\
\text { Asphaltenes }\end{array}$ & $0.01^{a}$ & $0.0075^{a}$ & $0.0075^{a}$ & $0.006^{a}$ & $0.006^{a}$ & 0.003 \\
\hline \multirow{2}{*}{4} & $\begin{array}{c}n C 5-n C 7 \\
\text { Asphaltenes }\end{array}$ & 0 & 0 & 0 & 0 & 0 & -0.009 \\
\hline & $\begin{array}{c}n C 7 \\
\text { Asphaltenes }\end{array}$ & 0 & 0 & 0 & 0 & 0 & -0.009 \\
\hline $5,6,7,8$ & Asphaltenes & 0 & 0 & 0 & 0 & 0 & -0.02 \\
\hline
\end{tabular}

${ }^{a}$ Modified in this work to decrease the deviations from the experimental data.

Table 14

The experimental density and calculated density using the PC-SAFT based approach-4, after adjusting aromaticity $(\gamma)$ of $A+R$, for Crudes- 5 to 8 .

\begin{tabular}{ccc}
\hline Crude & Experimental Crude density $(\mathrm{g} / \mathrm{cc})$ & Calculated Crude density $(\mathrm{g} / \mathrm{cc})$ \\
\hline 1 & 0.873 & 0.872 \\
3 & 0.982 & 0.951 \\
4 & 1.016 & 0.997 \\
5 & 1.001 & 1.002 \\
6 & 0.995 & 1.011 \\
7 & 0.928 & 0.927 \\
8 & 0.871 & 0.841 \\
\hline
\end{tabular}


Table 15

The number of Model Adjustable (MAP) Parameters for all the approaches calculated from experimental data of asphaltene precipitation.

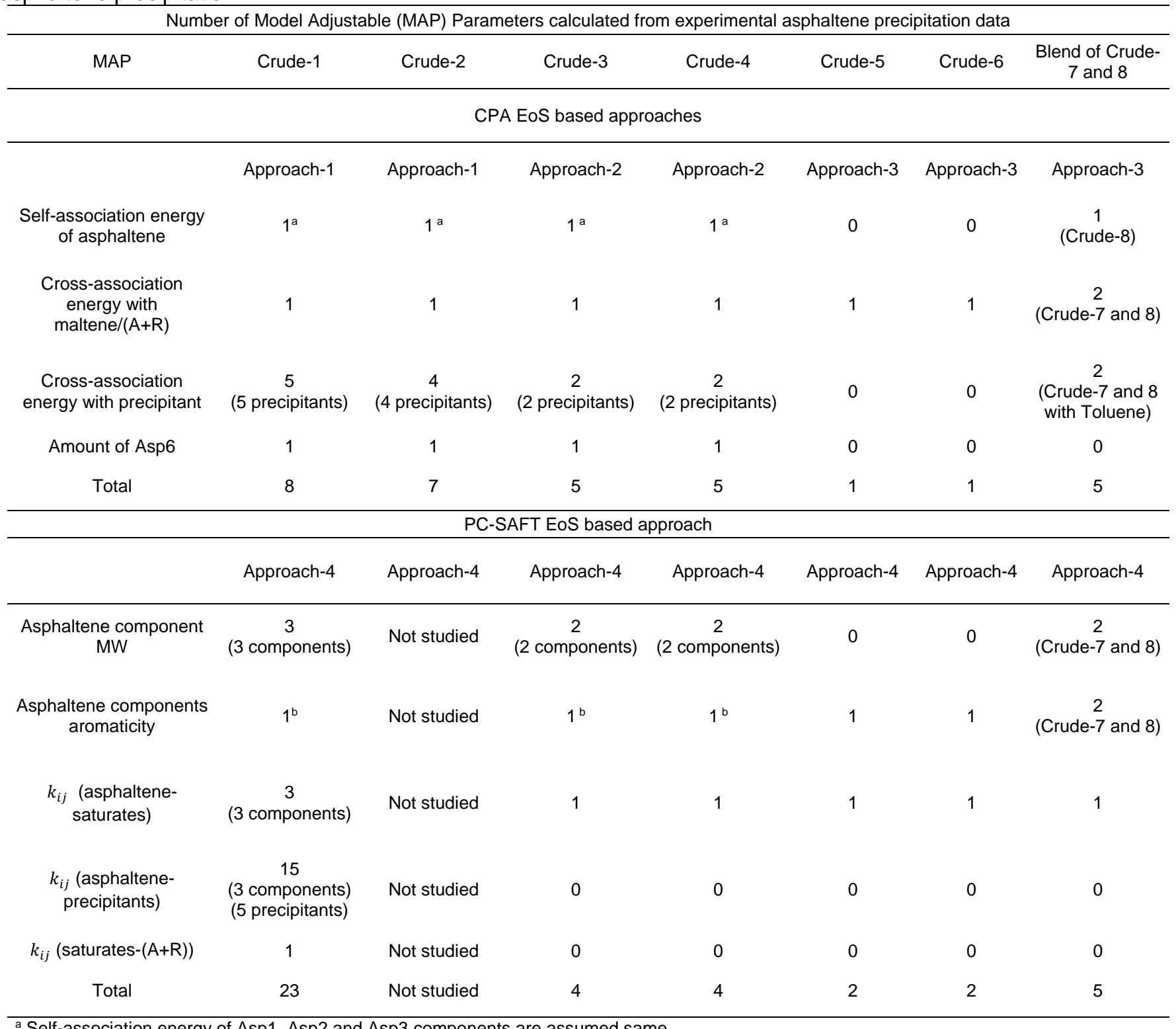

a Self-association energy of Asp1, Asp2 and Asp3 components are assumed same.

${ }^{\mathrm{b}}$ Aromaticity of all asphaltene components of the crude are assumed same. 


\section{Asphaltene Precipitation from Light Crudes}

Crude-1 is an Iranian crude whose information including the experimental data are referred from Hirschberg et al [2]. It is characterized using the CPA EoS based approach-1 and the PCSAFT EoS based approach-4. The characterization of the crude and model parameters for approach-4 are referred from the work of Tavakkoli et al [7]. Fig. 1a shows the experimental asphaltene yield for $n C 5, n C 7$, and $n C 10$ precipitants while Fig. $1 \mathrm{~b}$ shows the experimental concentration of precipitant $(n C 7, n C 10, n C 12$ and $n C 16)$ at the onset of asphaltene precipitation condition. Fig. $1 \mathrm{a}$ and $1 \mathrm{~b}$ show that both approaches can correlate the data but the accuracy of approach-1 is higher than approach-4. It should be noted that approach-4, with all $k_{i j}=0$, cannot predict the asphaltene precipitation during the addition of $n$-paraffin. However, as shown in Fig. $1 \mathrm{a}$, when $k_{i j}$ is used, as shown in Table 13, approach-4 can correlate the asphaltene precipitation data. The higher value of $k_{i j}$ (e.g. $k_{i j}$ with $n C 5$ is greater than that with $n C 7$ ) results in more asphaltene yield. From Fig. 1b, one can analyze that the difference between the approaches- 1 and 4 fitted results for the $n C 5$ concentration at the onset point is large since the higher value of $k_{i j}$ lowers the precipitant concentration at onset. From the approach-4 results, it can be concluded that it cannot predict both types of the experimental data (the asphaltene yield and onset condition for different $n$-paraffins) qualitatively. The approach- 1 results of onset conditions are not very sensitive to the cross-association energy of $n$-paraffin since the crossassociation between $n$-paraffin undissolved asphaltene (Asp6) component and $n$-paraffin is not considered. Therefore, approach-1 can predict both types of experimental data qualitatively. For approach-1, the difference between the values of cross-association energies for $n C 5$ asphaltenes and $n C 7$-asphaltenes pairs is higher than the difference between the values of cross-association energies for the $n C 7$-asphaltenes and $n C 10$-asphaltenes pairs. The two widely different values of the model parameters (cross-association energy in approach-1 and $k_{i j}$ value in approach-4) related to $n C 5$ and $n C 7$ precipitants are due to the widely different values of respective asphaltene yield. From the fitted results using both approaches, as shown in Fig. 1a, it is observed that the asphaltene yield decreases at higher dilution of $n C 7$ and $n C 10$. Hirschberg et al [2] did not mention the error margin on the experimental data. Wang and Buckley [28] concluded from their experimental studies that the asphaltene yield increases with the amount of $n$-paraffin, reaches a maximum value, then decreases at higher amount of $n$ paraffin. They observed the maximum in the asphaltene yield at around 30:1 to 40:1 nparaffin:oil volume ratio when $n C 6$ or $n C 7$ used. For $n C 5$, they observed the maximum at around 80:1 $n$-paraffin:oil volume ratio. They mentioned that the overall error on asphaltenes amount measurement was around $\pm 0.02 \mathrm{wt} \%$. 


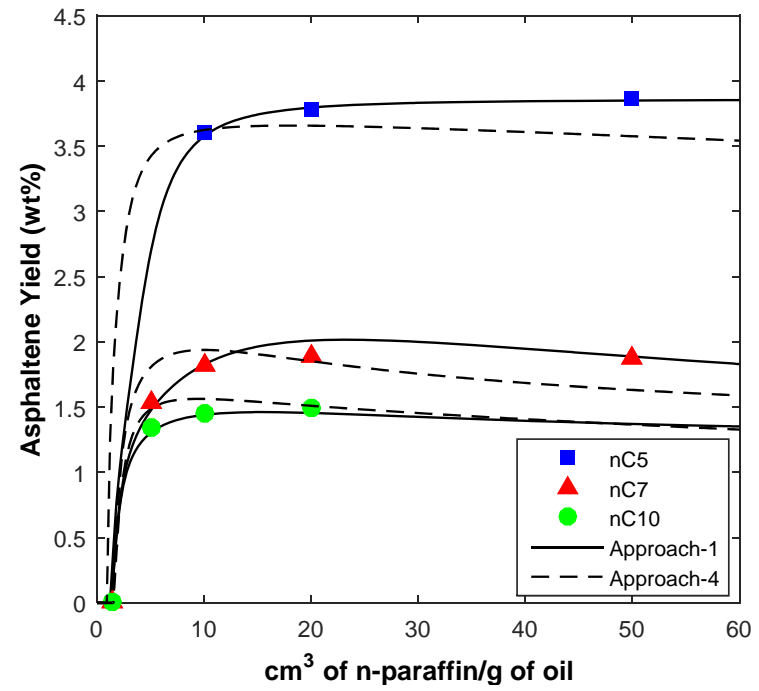

(a)

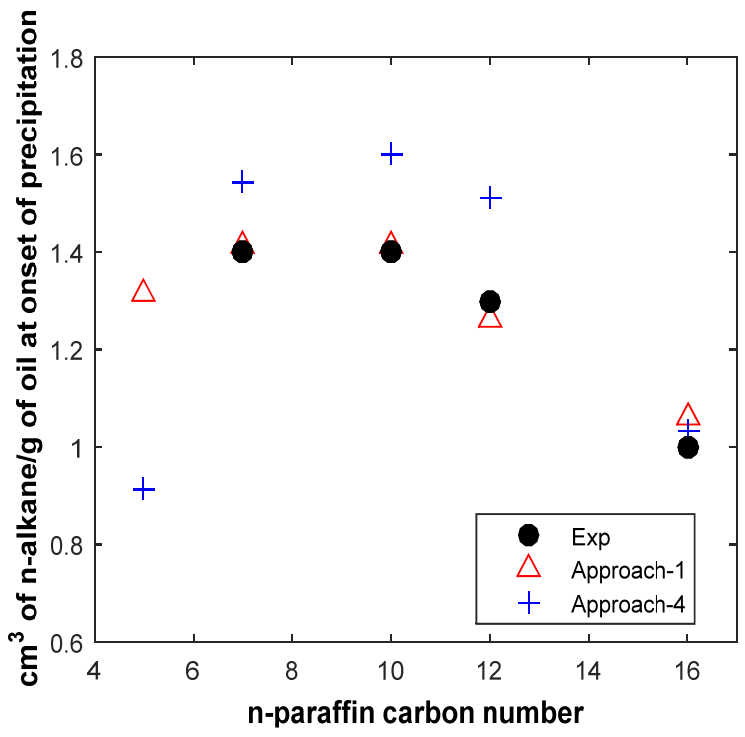

(b)

Fig. 1. Crude-1: (a) Asphaltene yield during the addition of $n C 5, n C 7$ and $n C 10$ paraffins. (b) Amount of different $n$ paraffins ( $n C 5, n C 7, n C 10, n C 12, n C 16)$ required at the onset of asphaltene precipitation. Experimental data are from Hirschberg et al [2]. All experimental data (Fig. 1a and 1b) are used for the parameters estimation.

Crude-2 is a Mexican crude whose information including the experimental data are referred from Buenrostro-Gonzalez et al [15]. The experimental data of the asphaltene yield for $n C 5$, $n C 7, n C 9$ and $n C 12$ precipitants are available. For this crude, only the CPA EoS based approach-1 is studied. Fig. 2 shows that approach-1 is able to correlate the data after calculating the model adjustable parameters. The PC-SAFT EoS based approach-4 could also predict this data but we could not fit the model due to the difficulty of estimation of a large number of model adjustable parameters. Buenrostro-Gonzalez et al [15] used the SAFT-VR EoS in McMillan-Mayer framework developed by Wu et al [16-17] to predict this experimental data (with seven adjustable model parameters), however, their model results are not as accurate as the results of this work. The reader is referred to their work for more detail. 


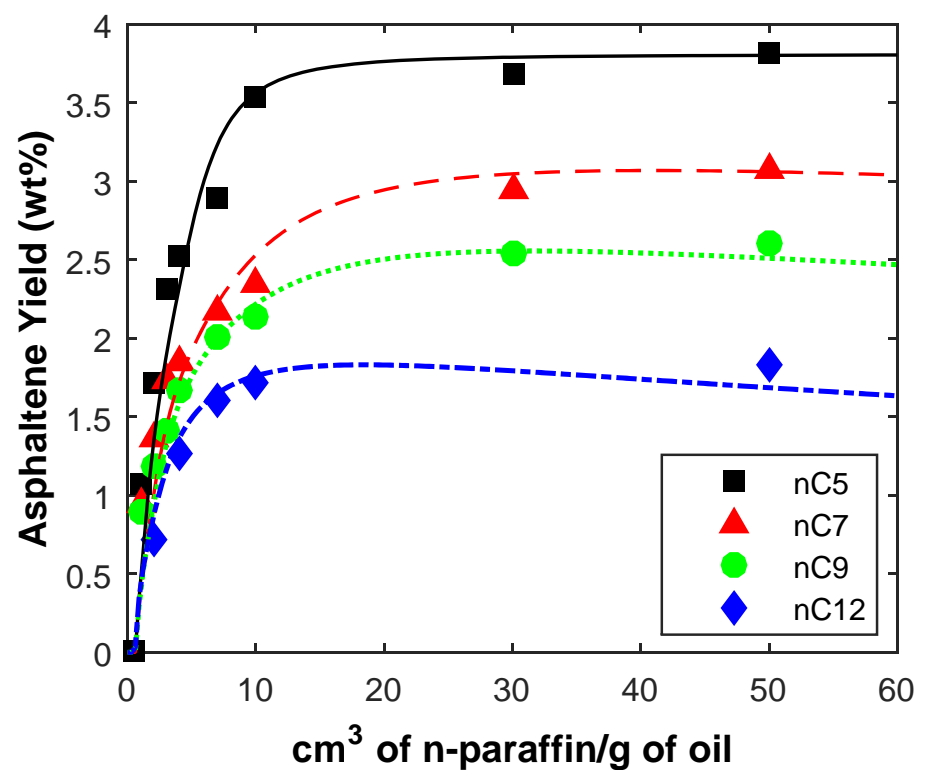

Fig. 2. Crude-2: Asphaltene yield during the addition of $n C 5, n C 7, n C 9$ and $n C 12$ paraffins. Lines represent the correlations using approach-1. Symbols represent the experimental data from Buenrostro-Gonzalez [15].

\section{Asphaltene Precipitation from Heavy Crudes}

Crude-3 and 4 are Russian and Venezuelan heavy oils respectively whose information including the experimental data are referred from Sabbagh et al [13]. They mentioned that the asphaltene yield data were repeatable to \pm 0.015 (wt/wt). For approach-4, the oil characterization and model parameters are referred from Tavakkoli et al [7]. For these crudes, the experimental data of asphaltene yield for $n C 5$ and $n C 7$ precipitants are available. As seen from Fig. 3a and 3b, approach-2 can correlate the data better than approach-4. For approach4 , only one $k_{i j}$, of negative value, between saturates and asphaltenes is used. The $k_{i j}$ value is used to correlate the onset condition. 


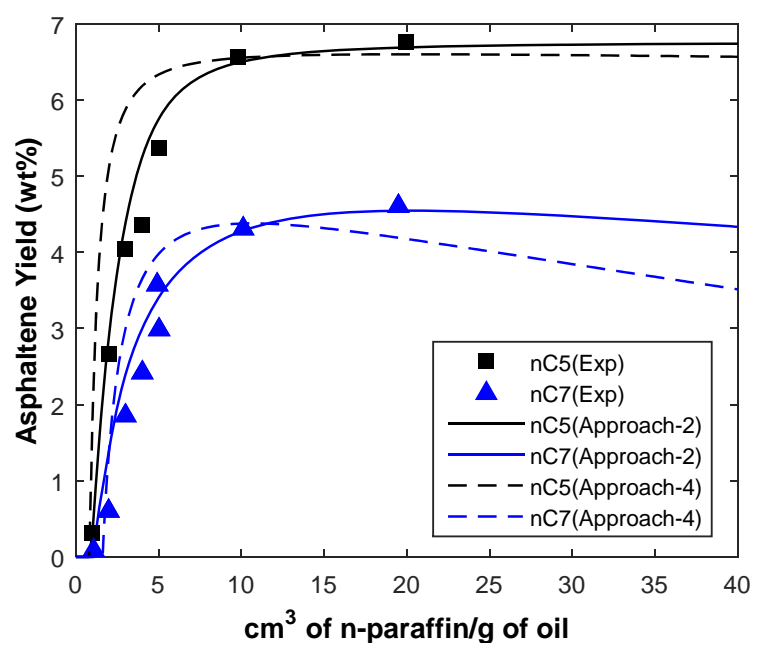

(a)

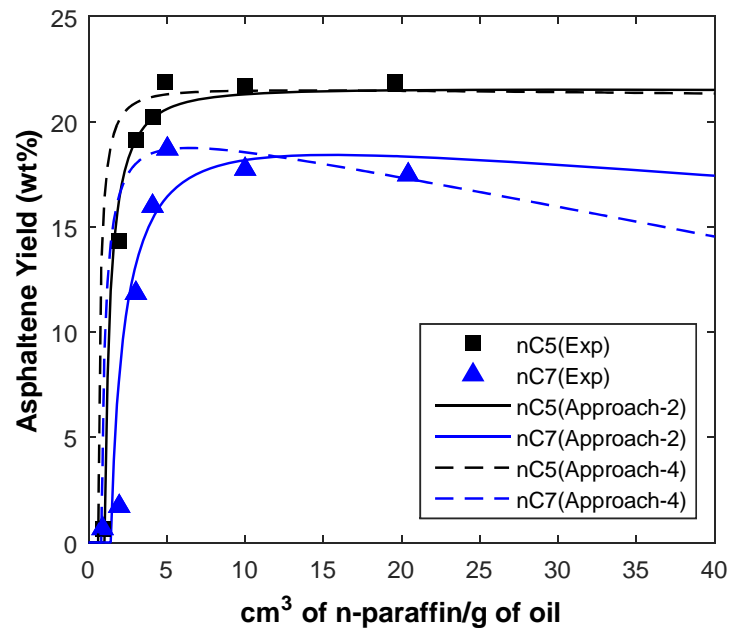

(b)

Fig. 3. (a) Crude-3: Asphaltene yield during the addition of $n C 5$ and $n C 7$ paraffins. (b) Crude-4: Asphaltene yield during the addition of $n C 5$ and $n C 7$ paraffins. Experimental data are from Sabbagh et al [13] for both Crude-3 and 4.

Fig. 4 shows the predictions of asphaltene yield for Crude- 3 for $n C 7, n C 9, n C 10$ and $n C 11$ precipitants using approach-4. One can see that for the $n C 10$ precipitant, the asphaltene yield is zero and the asphaltene yield for $n C 11$ is higher than that for $n C 9$, when precipitant concentration is $40 \mathrm{~cm}^{3} / \mathrm{g}$ of oil. However, it contradicts the general experimental behavior from the literature, where the asphaltene yield always decreases or remains almost constant as the carbon number of paraffinic solvent is increased. Therefore, we hypothesize that approach-4 needs $k_{i j}$ between asphaltenes and precipitant (like Crude-1) before calculating the PC-SAFT parameters of polydisperse asphaltene fraction. In other words, the asphaltene yield of the crude for different $n$-paraffins precipitants cannot be predicted using approach-4 but can be correlated considering $k_{i j}$ between asphaltenes and precipitant. It should be noted that approaches- 1 to 3 can also not predict the asphaltene yield for different $n$-paraffins and that is why the approach-2 predictions, like Fig. 4 for the approach-4 predictions, are not shown. The same behavior of the approach-4 results, like Fig. 4 for Crude-3, has been observed for Crude4 but results are not shown here. Therefore, one must check physical behaviors (mole fraction of $n$-paraffin at the precipitation onset, discussed later, and the asphaltene yield should decrease with the carbon number of $n$-paraffin) while calculating the model parameters. 


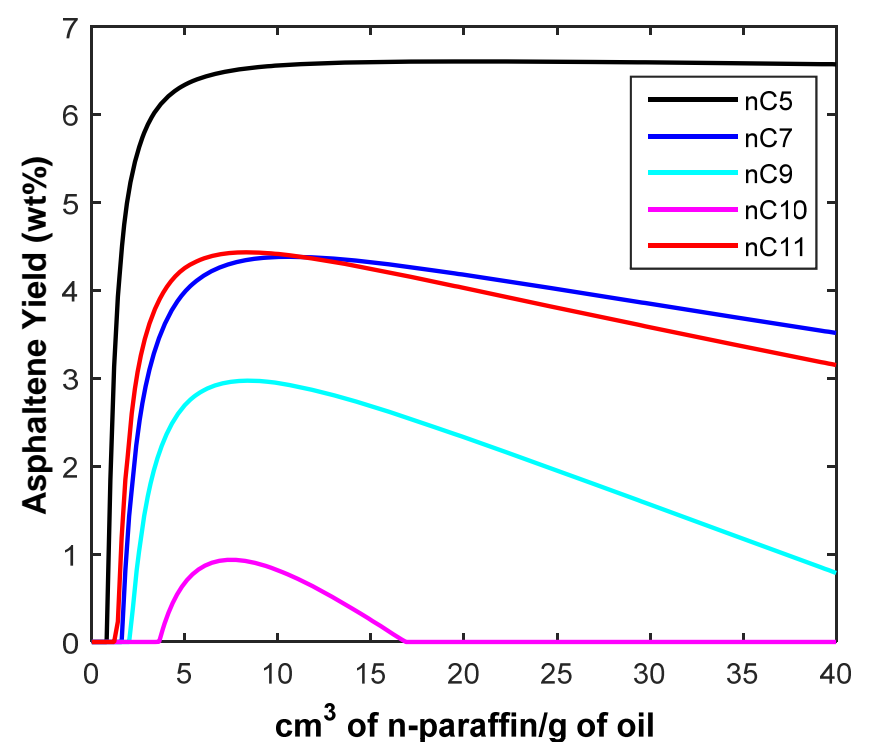

Fig. 4. Crude-3: Predictions of the asphaltene yield during the addition of different $n$-paraffins using approach-4.

\section{Asphaltene Precipitation Onsets for Heavy Crudes}

When the asphaltene precipitation onset conditions are modeled for the reservoir fluid (at high $\mathrm{T}$ and $\mathrm{P}$ ), the asphaltene fraction is usually considered as a monodisperse fraction/component since we are generally interested in calculating the onset conditions. Therefore, it is important to check whether the modeling approaches can predict the onset conditions when the asphaltene fraction is treated as a single component. Crude- 5 and 6 are Cold Lake Bitumen and Athabasca heavy oils respectively whose information including the experimental data are referred from Wiehe et al [11]. The experimental data of asphaltene onset conditions for different $n$-paraffins are available for these crudes. Wiehe et al [11] mentioned that the precision of the onset data is within 0.1 vol\%. Fig. $5 \mathrm{a}$ and $5 \mathrm{~b}$ show the experimental onset data and model fitted results on molar and volume basis respectively for Crude-5. Fig. 5a shows that the experimental g-moles of $n$-paraffin at the onset condition decreases with the $n$-paraffin carbon number. Fig. $5 \mathrm{~b}$ shows that the experimental data has a maximum at the $n$-paraffin carbon number of 9 . Fig. $5 a$ and $5 b$ show that approach- 3 correlates the experimental data qualitatively while approach-4 has major deviations. Approach-4 is studied with respect to scenarios-1 and 2. In scenario-1, the standard $n$-paraffin PC-SAFT parameters from Gross and Sadowski [26] are used while in scenario-2, the $n$-paraffin PC-SAFT parameters are calculated from the generalized MW correlations, as shown in Table 7. For all other crudes, approach-4 is studied with scenario-1 only. Approach-4 with scenario-1 introduces an inconsistent effect of carbon number that does not seem to exist in the experimental data as shown in Fig. 5. On the other 
hand, approach-4 with scenario-2 gives linear trend as shown in Fig. 5 . Therefore, the nonlinearity with scenario-1 is due to the inconsistent values of the PC-SAFT parameters for the $n$-paraffin (especially for $n C 7$ to $n C 10$ ). The other model parameters like the PC-SAFT parameters of other components and $k_{i j}$ values are kept the same for scenarios- 1 and 2 . The approach-4 with scenario-2 model fitted results on volume basis, as shown in Fig. 5b, have considerable deviations due to the poor predictions of the fitted results on mole basis shown in Fig. 5a. It should be noted that approach-4 with scenario- 2 still gives accurate prediction of the molar volume. Therefore, it can be concluded that the asphaltene onset precipitation is very sensitive to the PC-SAFT parameters and detailed study about it could give us more insight. For approach-4 with scenarios-1 and 2 , using $k_{i j}$ value for asphaltenes- $n$-paraffin pair could correlate the experimental onset data. The same conclusion, like Crude-5, can be drawn for Crude- 6 from Fig. 6. From Table 8, one can observe that Crudes-5 and 6 have almost similar properties and SARA fractions. For approach-4, a negative $k_{i j}$ value $(-0.02)$ between saturates and asphaltenes is used for both Crudes-5 and 6 to decrease the deviations from the experimental data. Since there are multiple sets of MW and aromaticity values, which give the same modeling results (for approach-4), the experimental MW for the asphaltene component is used to reduce the number of adjustable parameters and the aromaticity value is calculated from the experimental data. The results of mole fraction of $n$-paraffin at the asphaltene onset condition for crudes-1 to 6 are mentioned in the supplementary information.

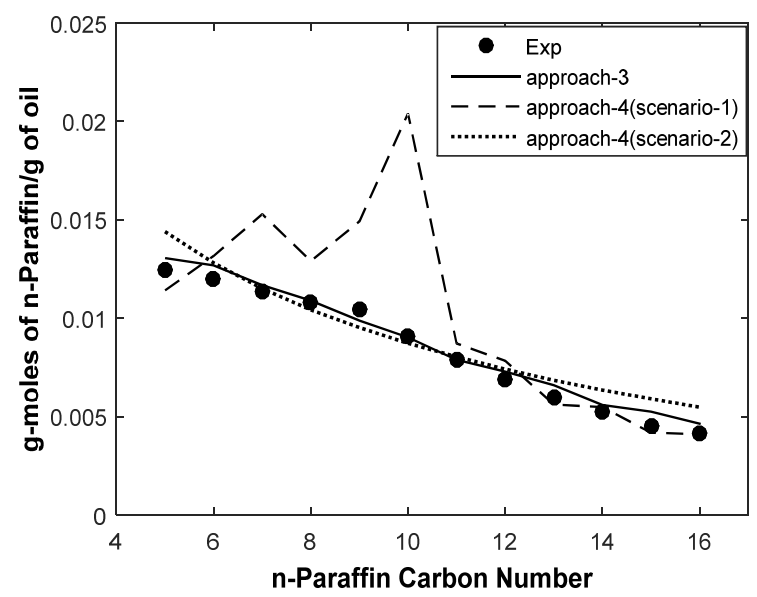

(a)

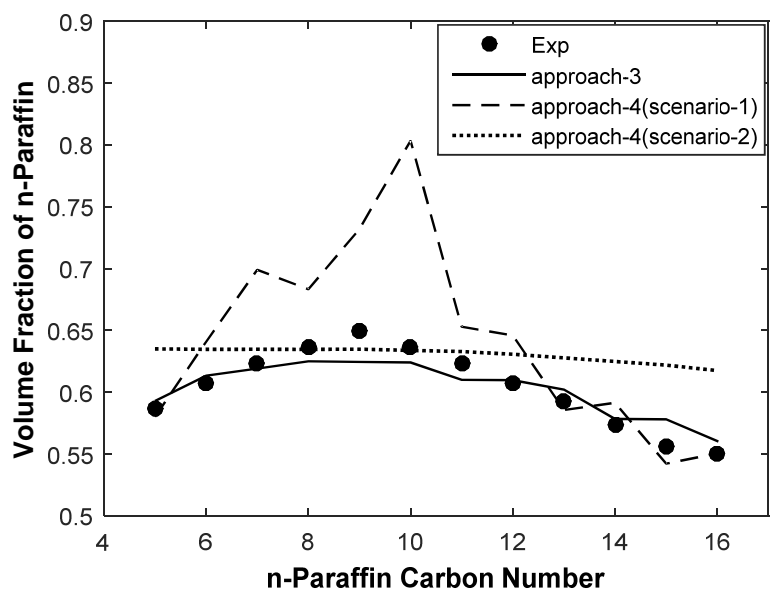

(b)

Fig. 5. Crude-5: (a) Amounts of $n$-paraffin on molar basis at the onset of asphaltene precipitation. (b) Amounts of $n$-paraffin on volume basis at the onset of asphaltene precipitation. Experimental data are from Wiehe et al [11]. Solid lines are from approach-3, dashed lines are from approach-4 with scenario-1, dotted lines are from approach4 with scenario-2. 


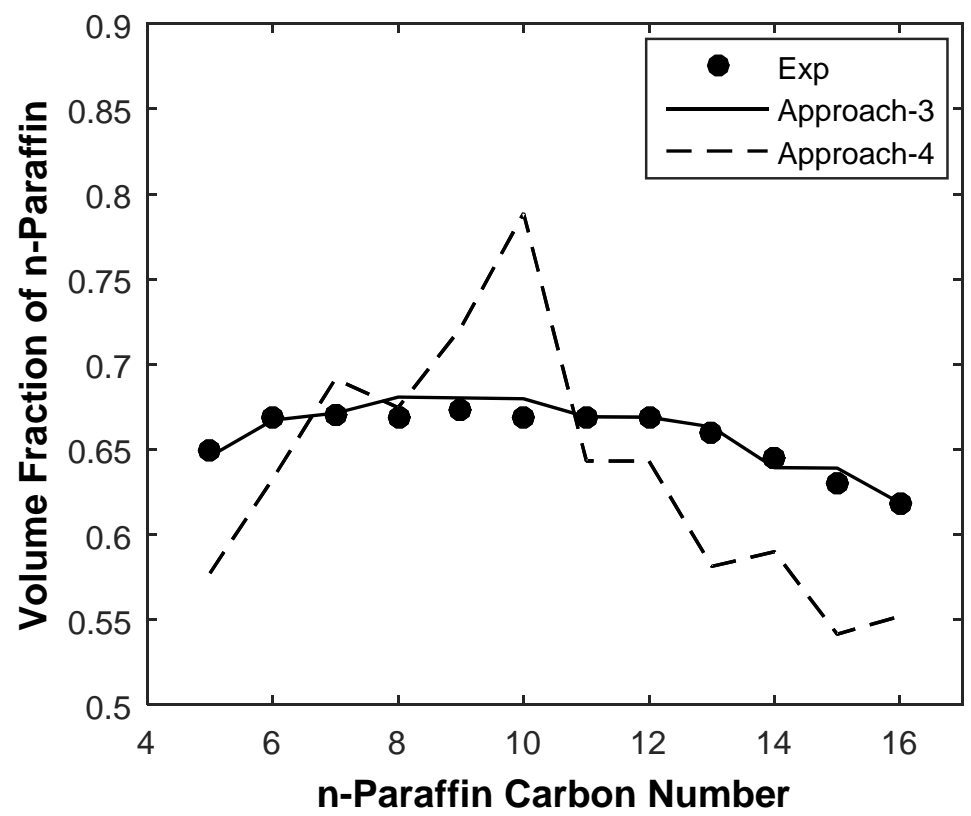

Fig. 6. Crude-6: Amounts of $n$-paraffin on volume basis at the onset of asphaltene precipitation. Experimental data are from Wiehe et al [11].

\section{Asphaltene Precipitation Onsets from Blending of Crudes}

In this section, the modeling approach to calculate the asphaltene precipitation onsets from the blends of Crudes-7 and 8 is discussed. Crudes-7 and 8 are from Gulf of Mexico and Middle East respectively whose information including the experimental data are referred from Tharanivasan et al [12]. They mentioned that the repeatability (in terms of relative standard deviation) of the measured yields was within $\pm 14 \%$ and $\pm 5 \%$ of the reported yield data at low ( $n$-heptane mass fraction <0.6) and high ( $n$-heptane mass fraction $>0.6$ ) dilution ratios respectively of crude oil or blend. The repeatability for the onset measurements was within $\pm 4 \%$ of the reported amount of $n$-heptane at the onset. The experimental data of $n C 7$ precipitant mass fraction at the onset of asphaltene precipitation from the blends of Crude- 7 or 8 with three different toluene concentrations are available as shown in Fig. 7. Also, the experimental data of $n C 16$ mass fraction at the onset of asphaltene precipitation from the blend of Crude- 7 with three different concentrations of Crude-8 are available as shown in Fig. 8. The approaches-3 and 4 parameters, as shown in Table 10 and 12 respectively, are calculated from the experimental data of Figs. 7 and 8 and the model fitted results are also shown in the same figures. As shown in Fig. 7, both approaches can correlate the experimental data. Fig. 8 shows 
that only approach-3 can correlate the non-linear behavior whereas approach-4 shows almost a linear trend between two extremes, which represent pure Crude- 7 result (left) and pure Crude8 result (right). For approach-3, this non-linearity increases with the difference between the selfassociation energies for the Crude- 7 and Crude- 8 asphaltenes. In other words, a large difference between the solubility parameters of asphaltene component of Crudes- 7 and 8 is required. However, for approach-4, the appropriate parameters could not be found, which can show the non-linearity. The minimum in this non-linear behavior is very important to decide the correct order of crudes to prepare the blend. For example, in this case, the minimum is close to the extreme of pure Crude-8 as shown in Fig. 8. Therefore, one should always prepare the blend by adding Crude- 8 into Curde- 7 and not the other way. The experimental data for the blend of Crude- 7 and Crude- 8 with three different toluene concentrations are also available as shown in Fig. 9. This figure shows that the approach-3 predictions have minor deviations while the approach-4 predictions have moderate deviations from the experimental data. One can also analyze that the trend between two extremes becomes more linear as the toluene concentration is increased. It would also be interesting to study the blend of three or more asphaltenic crudes, however, we could not find such experimental data from the literature.

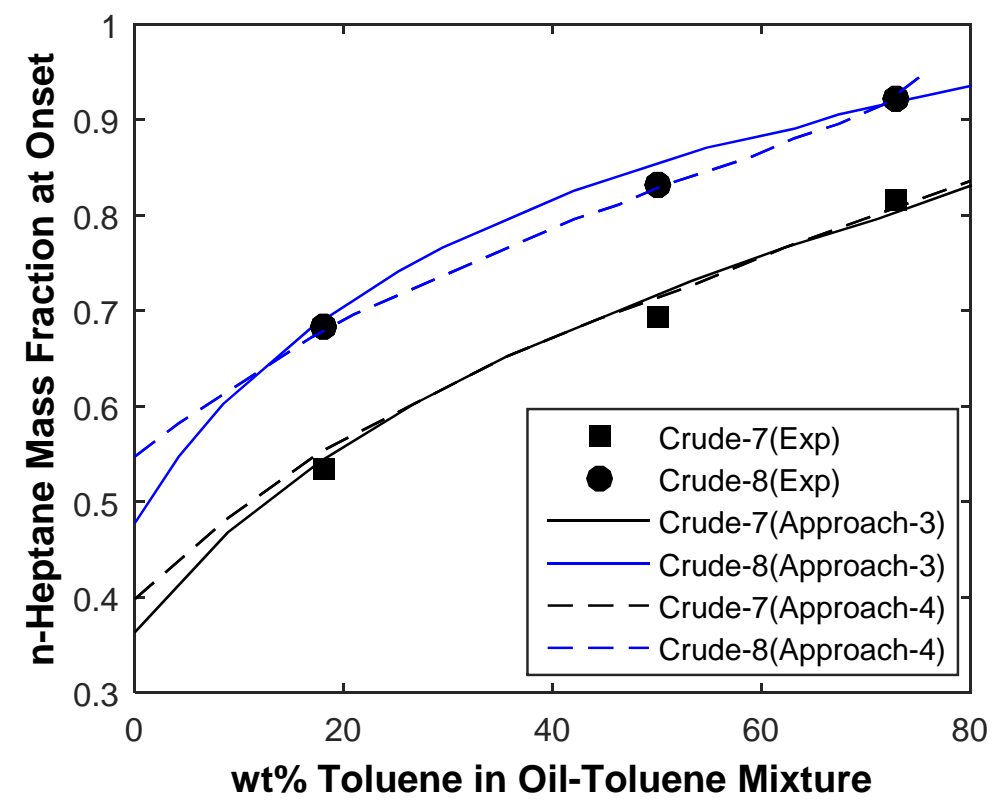

Fig. 7. Crude-7and 8: Amount of $n$-Heptane at the onset of asphaltene precipitation for the blend of different concentrations of crude oil and toluene. Experimental data are from Tharanivasan et al [12]. 


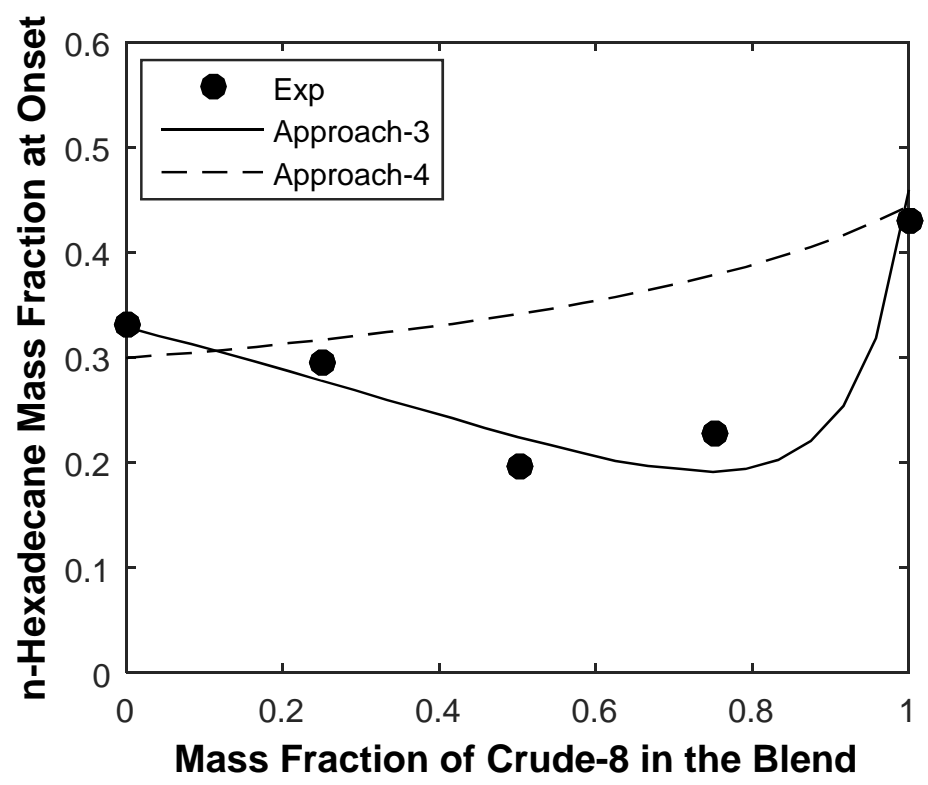

Fig. 8. Amount of $n$-Hexadecane at the onset of asphaltene precipitation for the blend of different concentrations of Crude-7 and 8. Experimental data are from Tharanivasan et al [12].

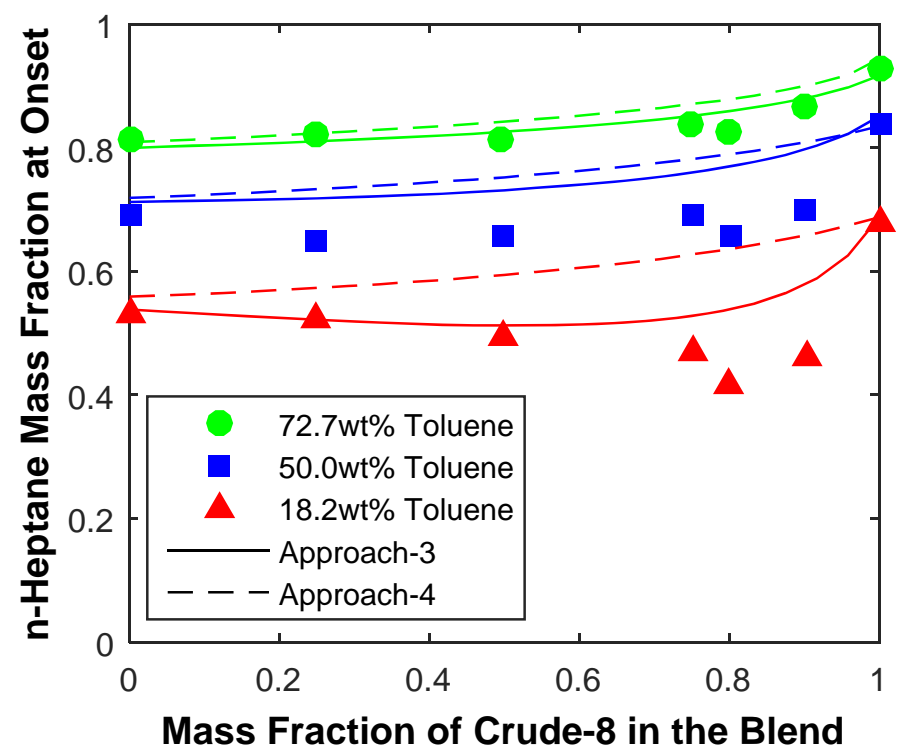

Fig. 9. Amount of $n$-Heptane at the onset of asphaltene precipitation for the blends of Crude-7, 8 and toluene at three different concentrations of toluene. Symbols represent the experimental data from Tharanivasan et al [12]. 


\section{Conclusions}

Based on the results found in this work we conclude that the solubility of asphaltene fraction in solvent at precipitation onset condition can be calculated from experimental data of onset composition for different $n$-paraffins precipitants. The solubility of asphaltene fraction is not dependent upon the number of solvent (maltene) components. The asphaltene fraction can be treated as monodisperse (single component) rather than polydisperse (multiple components) to calculate onset composition of the precipitant. The results for Crudes- 5 and 6 show that the CPA EoS based approach-3 (with one adjustable parameter) can accurately correlate the onset compositions of $n$-paraffins while the PC-SAFT EoS based approach- 4 without association term (with two adjustable parameters) has moderate deviations. Approach-4 needs binary interaction parameters to correlate the onset composition. With the modeling approaches used in this work, the asphaltene yield during the addition of a precipitant can only be correlated with given experimental data of asphaltene yield with the same precipitant. The approaches consider the asphaltene fraction as multiple components having different solubility parameters to correlate asphaltene yield. For the CPA EoS based approaches-1 and 2, different selfassociation energies are used to define multiple asphaltene components. For the PC-SAFT EoS based approach-4, different pure component parameters are used to define multiple asphaltene components. In addition, one adjustable parameter linked to the specific precipitant is also used. For approaches-1 to 3, it is the cross-association energy between precipitant and asphaltene. For approach-4, it is the $k_{i j}$ value between precipitant and asphaltenes. It is also shown from the results of Crudes- 3 and 4 that when $k_{i j}$ values (for $n$-paraffins- asphaltene pairs) for approach-4 are not used, the model predictions of asphaltene yield for different $n$ paraffins precipitants are not in agreement with the observed physical behavior of asphaltene precipitation: (a) In the first case it has been observed that the asphaltene yield decreases or remains constant with the carbon number of $n$-paraffin (b) In the second case the mole fraction of $n$-paraffin precipitant at onset condition is known to decrease with the carbon number of $n$ paraffin. A detailed study of the PC-SAFT parameters of $n$-paraffins (especially for $n$-heptane to $n$-decane) is required to establish monotonic trend of the mole fraction of $n$-paraffin precipitants at the onset conditions versus the carbon number of $n$-paraffin. It is also observed from the results of Crudes- 7 and 8 that approach- 3 correlates and predicts the non-linear trend of onset condition for the blend (Fig. 8 and 9) while approach-4 cannot. It should be noted that a similar approach based on the CPA EoS has already been studied with respect to the asphaltene precipitation onset conditions from the reservoir fluid in our previous studies [2022]. 


\section{Acknowledgement}

The authors wish to thank BP International limited (UK), Statoil (Norway) and Petrobras (Brazil) for supporting the work as part of the CHIGP (Chemical in Gas Processing) projects. The authors are grateful to Dr. Nikolaos Diamantonis and Dr. Leslie Bolton from BP International Limited (UK) for reviewing this article and providing constructive comments.

\section{List of Symbols}

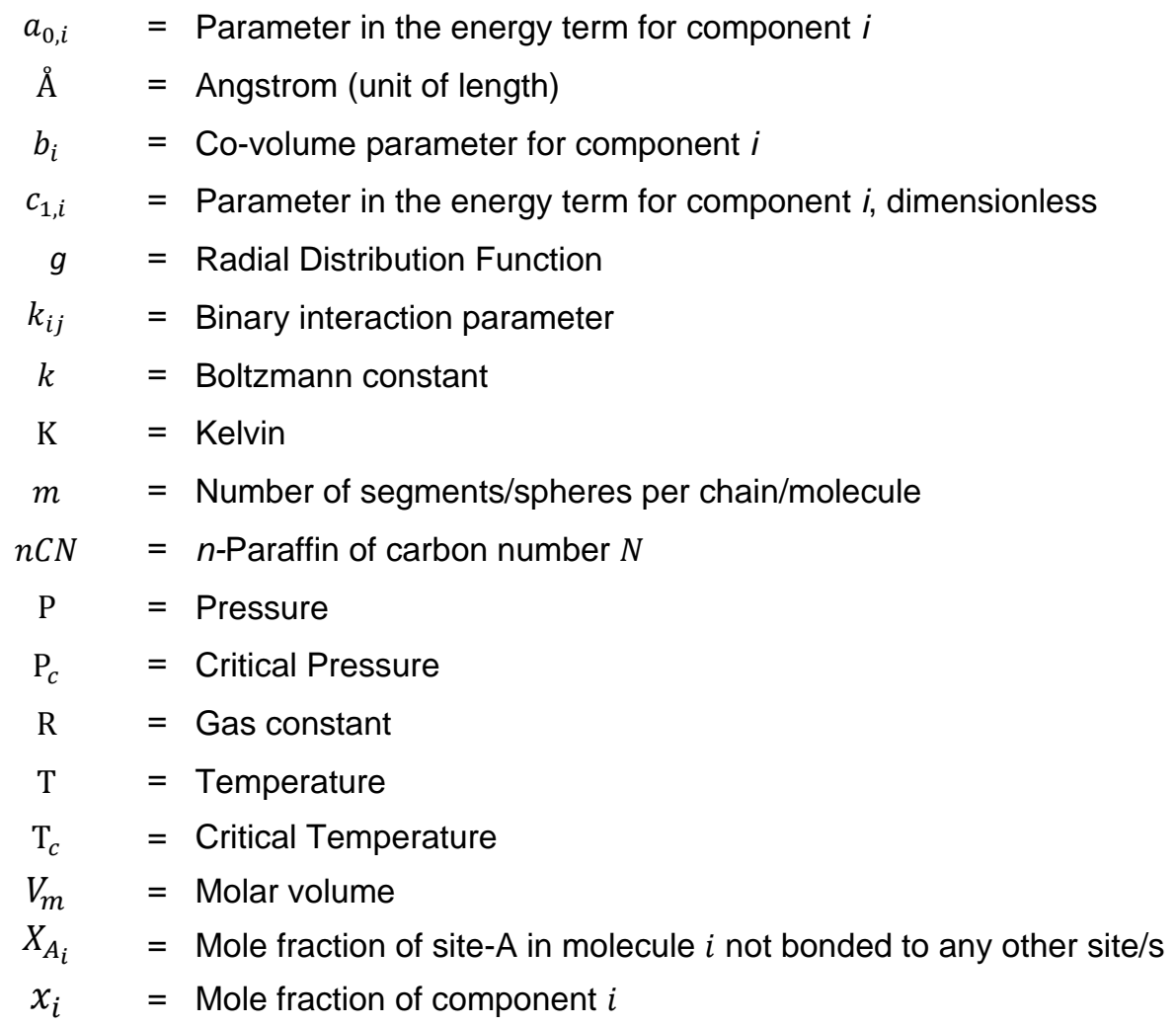

\section{Greek Letter}

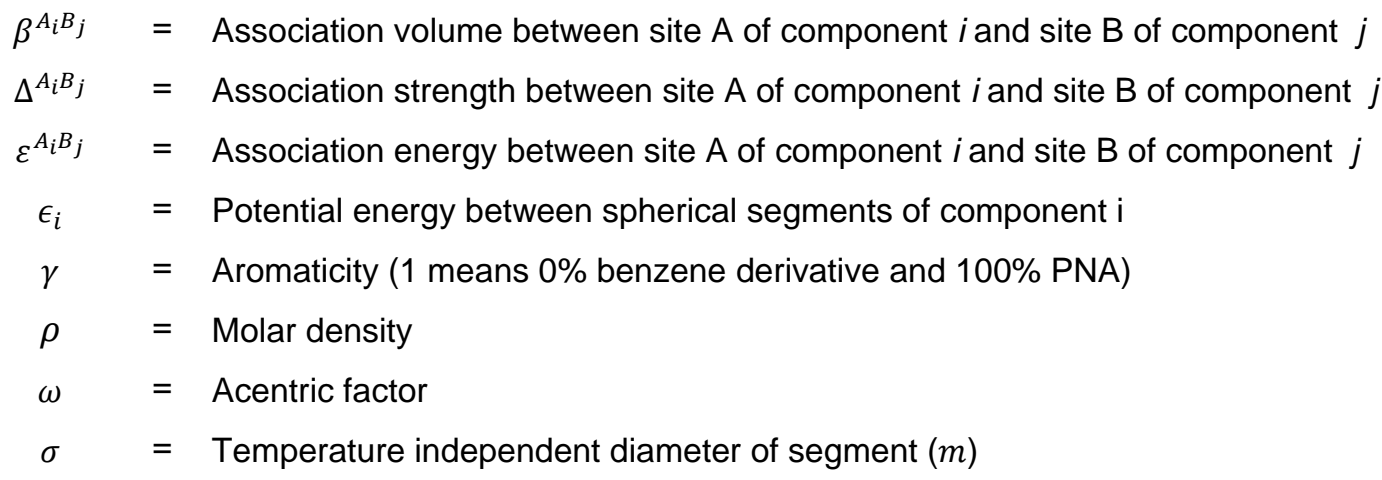




\section{List of Abbreviations}

$\begin{array}{ll}\text { Asp } & =\text { Asphaltene } \\ \text { A+R } & =\text { Aromatics+Resins } \\ \text { Calc } & =\text { Calculated } \\ \text { CERE } & =\text { Center for Energy Resources and Engineering } \\ \text { CPA } & =\text { Cubic Plus Association } \\ \text { Da } & =\text { Dalton } \\ \text { DTU } & =\text { Technical University of Denmark } \\ \text { EoS } & =\text { Equation of State } \\ \text { Exp } & =\text { Experimental } \\ \text { MW } & =\text { Molecular Weight } \\ \text { PC-SAFT } & =\text { Perturbed Chain Statistical Association Fluid Theory } \\ \text { PR } & =\text { Peng-Robinson } \\ \text { SAFT } & =\text { Statistical Associating Fluid Theory } \\ \text { SAFT-VR } & =\text { Statistical Associating Fluid Theory with Variable Range Potential } \\ \text { SARA } & =\text { Saturates Aromatics Resins Asphaltene } \\ \text { SG } & =\text { Specific Gravity } \\ \text { SRK } & =\text { Soave Redlich Kwong }\end{array}$




\section{References}

1 J. G. Speight, Petroleum Asphaltenes-Part 1: Asphaltenes, resins and the structure of petroleum, Oil and gas science and technology 59-5 (2004) 467-477.

2 Hirschberg, A., DeJong, L. N. J., Schipper, B. A., and Meijer, J. G. (1984). Influence of temperature and pressure on asphaltene flocculation. Society of Petroleum Engineers Journal, 24(03), 283-293.

3 F. Vargas, M. Garcia-Bermudes, M. Boggara, S. Punnapala, M.I. Abutaqiya, N.T. Mathew, H.Y. Al Asafen, On the Development of an Enhanced Method to Predict Asphaltene Precipitation, In Offshore Technology Conference held in Houston, Texas, USA, May-(2014).

4 Mitchell, D. L., and Speight, J. G. (1973). The solubility of asphaltenes in hydrocarbon solvents. Fuel, 52(2), 149-152.

5 Koots, J. A and Speight, J. G. (1975). Relation of petroleum resins to asphaltenes. Fuel, 54(3), $179-184$.

6 Wiehe, I. A., and Kennedy, R. J. (2000). The oil compatibility model and crude oil incompatibility. Energy fuels, 14(1), 56-59.

7 Tavakkoli, M., Panuganti, S. R., Taghikhani, V., Pishvaie, M. R., and Chapman, W. G. (2014). Understanding the polydisperse behavior of asphaltenes during precipitation. Fuel, 117, 206-217.

8 Alboudwarej, H., Akbarzadeh, K., Beck, J., Svrcek, W. Y., and Yarranton, H. W. (2003). Regular solution model for asphaltene precipitation from bitumens and solvents. AlChE Journal, 49(11), 2948-2956.

9 Akbarzadeh, K., Alboudwarej, H., Svrcek, W. Y., and Yarranton, H. W. (2005). A generalized regular solution model for asphaltene precipitation from n-alkane diluted heavy oils and bitumens. Fluid Phase Equilibria, 232(1), 159-170.

10 Pazuki, G. R., and Nikookar, M. (2006). A modified Flory-Huggins model for prediction of asphaltenes precipitation in crude oil. Fuel, 85(7), 1083-1086.

11 Wiehe, I. A., Yarranton, H. W., Akbarzadeh, K., Rahimi, P. M., and Teclemariam, A. (2005). The paradox of asphaltene precipitation with normal paraffins. Energy \& Fuels, 19(4), 1261-1267.

12 Tharanivasan, A. K., Svrcek, W. Y., Yarranton, H. W., Taylor, S. D., Merino-Garcia, D., and Rahimi, P. M. (2009). Measurement and modeling of asphaltene precipitation from crude oil blends. Energy \& Fuels, 23(8), 3971-3980.

13 Sabbagh, O., Akbarzadeh, K., Badamchi-Zadeh, A., Svrcek, W. Y., and Yarranton, H. W. (2006). Applying the PR-EoS to asphaltene precipitation from n-alkane diluted heavy oils and bitumens. Energy \& fuels, 20(2), 625-634.

14 Panuganti, S. R., Tavakkoli, M., Vargas, F. M., Gonzalez, D. L., and Chapman, W. G. (2013). SAFT model for upstream asphaltene applications. Fluid Phase Equilibria, 359, 2-16.

15 Buenrostro-Gonzalez, E., Lira-Galeana, C., Gil-Villegas, A., and Wu, J. (2004). Asphaltene precipitation in crude oils: Theory and experiments. AIChE Journal, 50(10), 2552-2570.

16 Wu, J., Prausnitz, J. M., and Firoozabadi, A. (1998). Molecular-thermodynamic framework for asphalteneoil equilibria. AIChE Journal, 44(5), 1188-1199.

17 Wu, J., Prausnitz, J. M., and Firoozabadi, A. (2000). Molecular thermodynamics of asphaltene precipitation in reservoir fluids. AIChE journal, 46(1), 197-209.

18 Li, Z., and Firoozabadi, A. (2010). Modeling asphaltene precipitation by n-alkanes from heavy oils and bitumens using cubic-plus-association equation of state. Energy \& Fuels, 24(2), 1106-1113.

19 G.M. Kontogeorgis, G.K. Folas, Thermodynamic models for industrial applications: from classical and advanced mixing rules to association theories. John Wiley and Sons (2009).

20 Arya, A., von Solms, N., and Kontogeorgis, G. M. (2015). Determination of asphaltene onset conditions using the cubic plus association equation of state. Fluid Phase Equilibria, 400, 8-19.

Page $\mathbf{2 9}$ of $\mathbf{3 0}$ 
21 Arya, A., von Solms, N., \& Kontogeorgis, G. M. (2015). Investigation of the Gas Injection Effect on Asphaltene Onset Precipitation Using the Cubic-Plus-Association Equation of State. Energy \& Fuels, 30(5), 3560-3574.

22 Arya, A., Liang, X., von Solms, N., and Kontogeorgis, G. M. (2016). Modeling of Asphaltene Onset Precipitation Conditions with Cubic Plus Association (CPA) and Perturbed Chain Statistical Associating Fluid Theory (PC-SAFT) Equation of States. Energy \& Fuels, 30(8), 6835-6852.

23 Kesler, M. G., and Lee, B. I. (1976). Improve prediction of enthalpy of fractions. Hydrocarbon processing, 55(3), 153-158.

24 Pedersen, K. S., Christensen, P. L., and Shaikh, J. A. (2014). Phase behavior of petroleum reservoir fluids. CRC Press.

25 Speight, J. G., Long, R. B., Trowbridge, T. D., and Linden, N. (1982). On the definition of asphaltenes. Am. Chem. Soc., Div. Pet. Chem., Prepr., 27(3), 268-275.

26 Gross, J., and Sadowski, G. (2001). Perturbed-chain SAFT: An equation of state based on a perturbation theory for chain molecules. Industrial \& engineering chemistry research, 40(4), 1244-1260.

27 Gonzalez, D. L., Hirasaki, G. J., Creek, J., and Chapman, W. G. (2007). Modeling of asphaltene precipitation due to changes in composition using the perturbed chain statistical associating fluid theory equation of state. Energy \& fuels, 21(3), 1231-1242.

28 Wang, J., and Buckley, J. (2007). Effect of dilution ratio on amount of asphaltenes separated from stock tank oil. Journal of dispersion science and technology, 28(3), 425-430. 